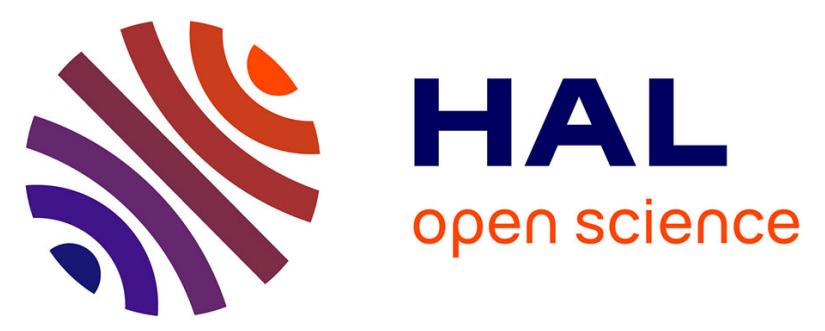

\title{
Ethanol Electro-oxidation on Palladium Revisited Using Polarization Modulation Infrared Reflection Absorption Spectroscopy (PM-IRRAS) and Density Functional Theory (DFT): Why Is It Difficult To Break the C-C Bond?
}

Evans A. Monyoncho, Stephan N. Steinmann, Carine Michel, Elena A. Baranova, Tom K. Woo, Philippe Sautet

\section{- To cite this version:}

Evans A. Monyoncho, Stephan N. Steinmann, Carine Michel, Elena A. Baranova, Tom K. Woo, et al.. Ethanol Electro-oxidation on Palladium Revisited Using Polarization Modulation Infrared Reflection Absorption Spectroscopy (PM-IRRAS) and Density Functional Theory (DFT): Why Is It Difficult To Break the C-C Bond?. ACS Catalysis, 2016, 2016 (6), pp.4894-4906. 10.1021/acscatal.6b00289 . hal-01343876

\author{
HAL Id: hal-01343876 \\ https://hal.science/hal-01343876
}

Submitted on 5 Dec 2018

HAL is a multi-disciplinary open access archive for the deposit and dissemination of scientific research documents, whether they are published or not. The documents may come from teaching and research institutions in France or abroad, or from public or private research centers.
L'archive ouverte pluridisciplinaire $\mathbf{H A L}$, est destinée au dépôt et à la diffusion de documents scientifiques de niveau recherche, publiés ou non, émanant des établissements d'enseignement et de recherche français ou étrangers, des laboratoires publics ou privés. 


\title{
Ethanol Electrooxidation on Palladium Revisited using
}

\section{PM-IRRAS and DFT: Why is it difficult to break the C -}

\section{C bond?}

Evans A. Monyoncho, ${ }^{a, b}$ Stephan N. Steinmann, ${ }^{c}$ Carine Michel, ${ }^{c}$ Elena A. Baranova,${ }^{b *}$ Tom K. Woo, ${ }^{a}$ and Philippe Sautet..$^{*}$

${ }^{a}$ Department of Chemistry and Biomolecular Sciences, Center for Catalysis Research and Innovation (CCRI), University of Ottawa, 10 Marie-Curie Private, Ottawa, Ontario K1N 6N5, Canada

${ }^{\mathrm{b}}$ Department of Chemical and Biological Engineering, (CCRI), University of Ottawa, 161 Louis-Pasteur St., Ottawa, Ontario K1N 6N5, Canada

${ }^{c}$ Univ Lyon, ENS de Lyon, CNRS, Université Lyon 1, Laboratoire de Chimie UMR 5182, F-69342, Lyon, France

\begin{abstract}
Insights into ethanol electrooxidation reaction mechanism on palladium in alkaline media are presented combining polarization modulation infrared reflection absorption spectroscopy (PM-IRRAS) and density functional theory (DFT) calculations. The synergy between PM-IRRAS and DFT calculations helps to explain why the $\mathrm{C}-\mathrm{C}$ bond is not broken during ethanol electrooxidation, and the reaction
\end{abstract}


stops at acetate. Coupling chronoamperometry (CA) with in-situ PM-IRRAS enabled us to simultaneously identify ethanol electrooxidation products on the catalyst surface and in the bulk solution. We show that at lower potential it is possible to break the $\mathrm{C}-\mathrm{C}$ bond on $\mathrm{Pd} / \mathrm{C}$ in alkaline media to form $\mathrm{CO}_{2}$. However, the selectivity is poor due to competition towards the formation of acetate and other side products, which gets worse at higher potentials. DFT calculations were used to complete the picture using the computational hydrogen electrode approach. The calculations highlight the pivotal role of the $\mathrm{CH}_{3} \mathrm{CO}$ intermediate that can either undergo a $\mathrm{C}-\mathrm{C}$ bond scission yielding $\mathrm{CO}$ and then $\mathrm{CO}_{2}$ or that can be oxidized towards $\mathrm{CH}_{3} \mathrm{COO}^{-}$. The latter is a dead end in the reaction scheme towards $\mathrm{CO}_{2}$ production, since it cannot be easily oxidized nor broken into $\mathrm{C}_{1}$ fragments. $\mathrm{CH}_{3} \mathrm{CO}$ is however not the most favored intermediate formed from ethanol electrooxidation on $\mathrm{Pd}$, hence limiting the production of $\mathrm{CO}_{2}$.

Keywords: Ethanol electrooxidation, Palladium, Spectroelectrochemistry, direct ethanol fuel cells, DFT, computational hydrogen electrode

\section{Introduction}

Fuel cells represent a promising technology for clean power generation because they convert chemical energy (fuel) into electrical energy with high efficiency and low-to-none emission of pollutants. ${ }^{1-4}$ Direct ethanol fuel cells (DEFCs) have several advantages compared to the most studied hydrogen and methanol fuel cells. First and foremost, ethanol is a non-toxic liquid, which lowers the investment of handling facilities because the current infrastructure for gasoline can be largely used. ${ }^{5,6}$ Second, ethanol can be conveniently produced from biomass, hence is carbon neutral which mitigates increasing atmospheric $\mathrm{CO}_{2}$. Last but not least, if completely oxidized to $\mathrm{CO}_{2}$, ethanol has a higher energy density 
than methanol since it can deliver 12 electrons per molecule following the anodic reaction in equation $(1):^{5}$

$$
\mathrm{CH}_{3} \mathrm{CH}_{2} \mathrm{OH}+12 \mathrm{OH}^{-} \rightarrow 2 \mathrm{CO}_{2}+9 \mathrm{H}_{2} \mathrm{O}+12 \mathrm{e}^{-} \quad E_{a}^{o}=+0.19 \mathrm{~V} / \mathrm{RHE}
$$

In a DEFC, equation (1) is counterbalanced at the cathode by the oxygen reduction reaction, generating a theoretical cell voltage of $1.14 \mathrm{~V}$. However, in practice ethanol is known to be partially oxidized to acetic acid (acetate in alkaline media) giving a maximum of 4 electrons as shown in equation (2):

$$
\mathrm{CH}_{3} \mathrm{CH}_{2} \mathrm{OH}+5 \mathrm{OH}^{-} \rightarrow \mathrm{CH}_{3} \mathrm{COO}^{-}+4 \mathrm{H}_{2} \mathrm{O}+4 \mathrm{e}^{-} \quad E_{a}^{o}=-0.20 \mathrm{~V} / \mathrm{RHE}
$$

The almost exclusive oxidation to acetic acid overshadows the attractiveness of DEFC considerably, as the energy density is divided by 3 . The standard potential of acetic acid formation indicates that a reaction path including acetic acid, leads to inevitable potential losses of about $0.4 \mathrm{~V}$ (difference between ideal potential for $\mathrm{CO}_{2}$ and acetic acid "production"). ${ }^{7}$

The development of alkaline fuel cells has mainly been hampered by the lack of stable and efficient anion exchange membranes. However, this challenge has been well tackled in recent years, ${ }^{8,98,9}$ allowing the development of alkaline fuel cells (AFCs) which are of particular technological interest due to their simple designs and ability to operate at low temperatures $\left(25-100{ }^{\circ} \mathrm{C}\right)$. In alkaline conditions, the kinetic of both the cathodic oxygen reduction and the anodic ethanol oxidation is facilitated. Furthermore, the expensive Pt catalyst can be replaced by the lower-cost and more active transition metals, for instance Pd. ${ }^{10-14}$

Therefore, to overcome the limitation of incomplete oxidation of ethanol to $\mathrm{CO}_{2}$, several studies have attempted to provide a better understanding of the ethanol oxidation on Pd-based catalysts using the previous extensive work on the ethanol oxidation on Pt-based catalysts in acidic conditions as a starting point. Although the detailed understanding of ethanol electrooxidation mechanism is complex and 
controversial, there is a general consensus on Pt-based catalysts in acidic conditions that the reaction exhibits the so-called "dual pathway mechanism" 15,16 or "consecutive-parallel mechanism". ${ }^{17}$ According to this dual path reaction scheme, two major pathways are in competition. In the $\mathrm{C}_{2}$ pathway, the $\mathrm{C}-\mathrm{C}$ bond does not break and ethanol is oxidized successively to acetaldehyde and then to acetic acid (acetate in alkaline). In the $\mathrm{C}_{1}$ pathway, the $\mathrm{C}-\mathrm{C}$ bond is broken, thus generating $\mathrm{C}_{1}$ fragments. These fragments are oxidized into $\mathrm{CO}$ and eventually $\mathrm{CO}_{2}$. When shifting to alkaline conditions, very few studies provide detailed molecular information. ${ }^{18-23}$ Christensen et al. have shown in several studies that the interfacial $\mathrm{pH}$ drops at higher potentials due to the $\mathrm{OH}^{-}$consumption that is not completely counterbalanced by the $\mathrm{OH}^{-}$diffusion from the bulk to the interfacial region. ${ }^{22-24}$ This phenomenon leads to a transition from alkaline to effectively acidic conditions. The transition potential varies with the diffusion rate of $\mathrm{OH}^{-}$, i.e., working temperature, flow-rate and so on. They report that during electrooxidation reaction, ethanol is converted to acetate in alkaline $\mathrm{pH}$ while above the transition potential, i.e., in pseudo-acidic conditions, it yields acetic acid and trace amounts of $\mathrm{CO}_{2}$ as a result of the slow $\mathrm{C}-\mathrm{C}$ bond splitting. ${ }^{25}$ This is in agreement with the results from online mass-spectrometry, evidencing $\mathrm{CO}_{2}$ production over $\mathrm{Pt}$ and $\mathrm{Pd}$ in $0.01 \mathrm{M} \mathrm{NaOH}$, where acetic acid formation is almost absent. $^{26}$

On Pd-based electrocatalysts, ethanol oxidation reactivity differs compared to $\mathrm{Pt}$, which is illustrated most clearly in acidic conditions, where Pt yields mainly acetic acid and even some $\mathrm{CO}_{2}$, while $\mathrm{Pd}$ is completely inactive. ${ }^{27}$ In alkaline conditions, $\mathrm{Pd}$ is more active and it is generally proposed that ethanol is dehydrogenated into adsorbed acetyl $\left(\mathrm{CH}_{3} \mathrm{CO}\right)$ (sometimes erroneously called ethoxy) which is further oxidized to acetate by the hydroxyl $\left(\mathrm{OH}^{-}\right)$species. ${ }^{28}$ This mechanism has received further credence using in-situ attenuated total reflection surface-enhanced infrared absorption spectroscopy (ATRSEIRAS) measurements. ${ }^{19}$ Yang et al. reported that ethanol oxidation starts with the $\alpha-\mathrm{C}-\mathrm{H}$ bond 
scission yielding adsorbed $\mathrm{CH}_{3} \mathrm{CO}$ as a pivotal intermediate, which may be further oxidized into acetate or, given enough time, would fragment into $\mathrm{C}_{1}$ adsorbed intermediates (due to observation of adsorbed CO).${ }^{19}$ These observations can be rationalized by recalling that the oxidation of acetyl to acetate is an electrochemical step, and therefore favored by oxidative potentials, while the $\mathrm{C}-\mathrm{C}$ bond cleavage is expected to be only weakly affected by the potential, assuming that this process is not coupled with an electrochemical step such as the $\mathrm{C}-\mathrm{OH}$ bond formation.

To complement the experimental insights, modeling studies are also being reported. However, the complexity of the $\mathrm{Pd} / \mathrm{alkaline}$ electrochemical interface not only challenges experiments but also the atomistic modeling of the underlying mechanism. ${ }^{29}$ The main ingredients are the electrolyte and its $\mathrm{pH}$, both influencing the reactivity directly (state of the electrode surface) and indirectly (modifying the environment). The electrochemical potential and the inclusion of well-established equilibria, such as the reactivity of acetaldehyde (e.g., enol and aldol formation) or of $\mathrm{CO}$, which can be hydrated to yield formic acid adds to the complexity of the reaction network. It is currently impossible to consider all these aspects on a consistent level in one, exhaustive, study. Furthermore, the size of the "straight forward" reaction network for ethanol oxidation already includes 128 potential $C_{2}$ and $21 C_{1}$ intermediates.

The influence of co-adsorbed species and of explicit water molecules has intrigued several groups. In particular, Neurock and co-workers have modeled ethanol oxidation by $\mathrm{O}_{2}$ in alkaline conditions by including the aqueous media explicitly and adsorbed hydroxyl on the Pd surface. ${ }^{30}$ They have shown that most of the $\mathrm{C}-\mathrm{H}$ and $\mathrm{O}-\mathrm{H}$ scissions of the ethanol oxidation network towards acetic acid/acetate have lower barriers when assisted by co-adsorbed hydroxyl on $\operatorname{Pd}(111)$ compared with the bare metal. According to their results, acetaldehyde is a first intermediate towards acetic acid. Then, two possibilities exist: (i) the geminal diol, which can be formed by hydration of the acetaldehyde in 
solution, leads straightforwardly to acetic acid (ii) acetaldehyde is either oxidized by the direct formation of a $\mathrm{C}-\mathrm{OH}$ bond, or the $\alpha-\mathrm{C}-\mathrm{H}$ bond is broken, leading to acetyl $\mathrm{CH}_{3} \mathrm{CO}$. In a more recent study, $\mathrm{Hu}$ and coworkers revisited this mechanism in the electrochemical context, but without accounting for the electrochemical potential. Their conclusions are in line with the ones of Neurock regarding the oxidation by oxygen using a more advanced description of the structure of the water solvent. ${ }^{31}$ It should be noted that under electrochemical conditions, surface $\mathrm{OH}$ is also formed in acidic conditions, provided the electrochemical potential is sufficiently positive. ${ }^{32}$ As a consequence, these simulations can be applied to both alkaline and acidic conditions.

In order to complement these studies, one should include the effect of the electrochemical potential. The electrochemical potential can be included at various levels of sophistication. The most important effects are due to a change in thermodynamics when electrons and protons are exchanged. This effect can be easily obtained as a posteriori correction to ab initio energies (typically periodic DFT) as originally proposed by Norskov, known as the computational hydrogen electrode. ${ }^{7}$ This approach has been used successfully for $\mathrm{MeOH}$ oxidation on a large range of metals ${ }^{33-35}$ and includes the thermodynamic driving force of the $\left(\mathrm{H}^{+}, \mathrm{OH}^{-}\right)$recombination into $\mathrm{H}_{2} \mathrm{O}$. Several groups have also proposed strategies to include the influence of the potential in the electronic structure computations. ${ }^{36-41}$ Although more accurate, these approaches are also computationally more costly since they require the inclusion of the electrolyte to mimic adequately the capacitance of the interface, either with a continuum model ${ }^{42}$ a Poisson-Boltzmann theory, ${ }^{40,43}$ or an explicit, but static description. ${ }^{44}$ These approaches have been used for the study of small reaction path networks such as the $\mathrm{CO}_{2}$ hydrogenation to formic acid ${ }^{45}$ in combination with continuum models for the solvent or methanol and CO oxidation at a Pt catalyst. ${ }^{46,47}$

The aim of this work is to provide insights as to why the $\mathrm{C}-\mathrm{C}$ bond is not broken during ethanol electrooxidation and to propose a detailed mechanistic schematic, which can be applied in understanding 
experimental observations. Ethanol oxidation potentials were determined by cyclic voltammetry (CV). Chronoamperometry (CA), coupled with in-situ polarization modulation infrared reflection absorption spectroscopy (PM-IRRAS), was used to identify the oxidation products both on the catalyst surface and in the bulk solution. Density functional theory (DFT) calculations are exploited to explore all possible intermediates including the electrochemical potential using the computational hydrogen electrode at an alkaline $\mathrm{pH}$ of 14 . This setup allows us to include the thermodynamic effect of the involvement of hydroxide ions in the reaction mechanism without explicitly co-adsorbing $\mathrm{OH}$ on the catalyst surface. The potential energy profiles of the reactions were used to determine the most likely reaction pathway towards acetate on two different facets, $\operatorname{Pd}(111)$ and $\mathrm{Pd}(100)$. On the most active facet, a complete study of the $\mathrm{C}_{2}$ and $\mathrm{C}_{1}$ intermediates was done on the full range of the 12 electron oxidation (from ethanol to $\mathrm{CO}_{2}$ ) to select the key intermediates for the $\mathrm{C}-\mathrm{C}$ bond breaking. Besides, for the first time to the best of our knowledge, we assess the $\mathrm{C}-\mathrm{C}$ bond breaking from these key intermediates in the context of electro-oxidation. The energy barriers provide general strategies for improving the catalyst towards $\mathrm{C}-$ C bond scission.

\section{Experimental and computational methods}

\subsection{Palladium nanoparticles synthesis and characterization}

The Pd/C nanoparticles (NPs) were prepared using a polyol method reported in literature. ${ }^{48,49}$ In the synthesis, $0.25 \mathrm{~g}$ of anhydrous Palladium chloride (Fisher) was dissolved in $50 \mathrm{~mL}$ of ethylene glycol (EG) (Fisher) and the $\mathrm{pH}$ was adjusted to 8 by adding $0.06 \mathrm{M} \mathrm{NaOH}$ in EG. The solution was then refluxed at $160^{\circ}$ for 2 hours to form nanoparticles. To the resulting colloids, the appropriate amount of carbon black (Vulcan XC - 72 Cabot, Corp.) was added to obtain supported catalysts of 20 wt $\%$ loading. The mixture was stirred for 48 hours to achieve high dispersion of nanoparticles in carbon. The 
supported catalyst was thoroughly washed with de-ionized water $(18 \Omega \mathrm{cm})$ to remove EG and salt ions through vacuum filtration and air dried at $100{ }^{\circ} \mathrm{C}$ for 4 hours.

The details of physicochemical characterization techniques have been reported in the previous publication. ${ }^{49}$ In summary, the following techniques were used: The High-Angle Annular dark-field (HAADF) scanning transmission electron microscopy (STEM). The FEI Titan3 80-300 microscope model equipped with a CEOS aberration corrector for the probe forming lens and a monochromatic field-emission gun was used. X-ray diffraction pattern (XRD) was collected using a Rigaku Ultima IV diffractometer using a $\mathrm{Cu} \mathrm{K} \alpha$ X-ray source $(\lambda=1.54183 \mathrm{~A}, 40 \mathrm{kV}, 44 \mathrm{~mA})$. X-ray photoelectron spectroscopy (XPS) measurements were performed in a KRATOS Axis Ultra DLD with a Hybrid lens mode at $140 \mathrm{~W}$ and pass energy of $20 \mathrm{eV}$ using a monochromatic $\mathrm{Al} \mathrm{K} \alpha$.

\subsection{Spectroelectrochemical measurements}

All experiments were conducted at room temperature in a customized in-situ cell made of Teflon equipped with a hemi-cylinder $\mathrm{CaF}_{2}$ window (RJ Spectroscopy Co.). A glassy carbon (GC) electrode of $0.1962 \mathrm{~cm}^{2}$ geometric surface area was used as the current collector for carbon supported Pd NPs. All potentials were measured with respect to mercury-mercury oxide $(\mathrm{Hg} / \mathrm{HgO})$ (Koslow scientific) but reported versus the reversible hydrogen electrode $\left(\mathrm{E}_{(\mathrm{RHE})}=\mathrm{E}_{(\mathrm{Hg} / \mathrm{HgO})}+0.855\right.$ vs RHE), unless otherwise stated. A Pt wire served as a counter electrode. $1 \mathrm{M}\left(\mathrm{KOH}+\mathrm{C}_{2} \mathrm{H}_{5} \mathrm{OH}\right)$ was used as the electrolyte and was continuously purged with nitrogen gas. The catalyst ink was prepared by dispersing $6 \mathrm{mg}$ of $\mathrm{Pd} / \mathrm{C}$ powder in $1 \mathrm{ml}$ of de-ionized water, $200 \mu \mathrm{L}$ of isopropanol, and $100 \mu \mathrm{L}$ of Nafion solution. The mixture was sonicated for 10 min to form a homogeneous mixture. The ink solution $(10 \mu \mathrm{L})$ was deposited onto the GC-electrode surface and air dried at room temperature for $15 \mathrm{~min}$ and used as the working electrode. 
The PM-IRRAS measurements were performed using a Bruker Tensor 37 spectrometer equipped with an external Polarization Modulation Accessory (PMA $50 \mathrm{XL}$ ), nitrogen cooled mercury cadmium telluride detector (LN-MCT Narrow PMA50, Infrared Associates Inc., Stuart, FL), photoelastic modulator (PEM-100 controller with II/ZS50 ZnSe, $50 \mathrm{kHz}$ optical head, Hinds Instruments, Hillsboro, OR), and a demodulator [Synchronous Sampling demodulator (SSD), GWC Instruments, Madison, WI]. Electrode potential was controlled by a BioLogic VSP potentiostat equipped with the EC-Lab software (BioLogic Science Instruments SAS, Claix, France). The cell and PMA-50 XL chamber were thoroughly purged with nitrogen gas to remove background atmospheric $\mathrm{CO}_{2}$ and water vapour. Although the electrolyte was degassed with $\mathrm{N}_{2}$ before being introduced into the cell, it was degassed for 30 minutes once assembled in the optical path, and then the electrode was pushed against the $\mathrm{CaF}_{2}$ window without stopping the gas flow. The thin-cavity obtained was wedged in form but the average thickness was estimated ${ }^{50}$ to be $10 \mu \mathrm{m}$. Background spectra were collected to track the level of $\mathrm{CO}_{2}$ in the system. Typically, after two hours the reference spectrum was acquired at the open circuit potential (OCP) followed by sample spectra at various ethanol oxidation potentials selected from the cyclic voltammetry (CV) profile. Sample spectra were acquired under chronoamperometry (CA) conditions at five minutes increments i.e. while holding the potential constant for up to 30 minutes before stepping to another potential.

The signal was acquired by co-addition of 256 interferograms (128 forward and 128 backward scans) collected with a resolution of $8 \mathrm{~cm}^{-1}$. With PM-IRRAS, we are able to simultaneously measure the average reflectivity $\left[R_{\text {avg }}=\left(R_{p}+R_{s}\right) / 2\right]$ and the difference reflectivity $\left[R_{\text {dif }}=\left(R_{p}-R_{s}\right)\right]$ channel with a single detector because of its double-modulation scheme. ${ }^{51}$ The $\mathrm{R}_{\mathrm{p}}$ and $\mathrm{R}_{\mathrm{s}}$ are the reflecties for $\mathrm{p}$ - and spolarized light, respectively. Although this property comes with many advantages it presents a challenge in processing and interpretation of the data obtained. However, we have recently developed an approach 
to overcome this challenge which significantly simplifies PM-IRRAS data interpretation. The details for data processing are presented in the supporting information under "PM-IRRAS Data Processing and Interpretation" which will also be published later together with the detailed experimental optimization procedures in a manuscript currently under preparation ("Polarization Modulation Infrared Reflection Absorption Spectroscopy (PM-IRRAS) Utility in Electrocatalysis: Experimental and Data Processing Details" by Evans A. Monyoncho, Vlad Zamlynny, Tom K. Woo, and Elena A. Baranova) In summary, the approach yields strong signal-to-noise ratio enabling us to see weak absorption bands with a very few scans $(16$ - 256). The approach also allows direct interpretation of the spectra, and gives more insights of the substrate-film system or the reaction mechanism. The signal is reported as absorbance (A) using equation 3 and 4 which corresponds to surface and bulk-solution species, respectively.

$$
\begin{aligned}
& A=\log \left(\frac{\text { Sample }\left(R_{\text {dif }}\right)}{\text { References }\left(R_{\text {dif }}\right)}\right) \\
& \mathrm{vs} \mathrm{cm}^{-1}
\end{aligned}
$$

With this definition, the positive and negative bands in the spectra correspond to species produced or consumed at the sampling potential, respectively with respect to the reference spectrum.

\subsection{Computational methods}

Density functional theory (DFT) calculations were performed with the Vienna Ab-initio Simulation Package (VASP version 5.3.3). ${ }^{52,53}$ The generalized gradient approximation of Perdew, Burke, and Erzenhorf $(\mathrm{PBE})^{54}$ was used to compute the exchange-correlation energy. The projected augmented wave (PAW) method ${ }^{55,56}$ was employed to describe the core-electron interaction. A plane-wave basis set with an energy cut-off was set to $400 \mathrm{eV}$ was used. The Pd surfaces were modeled by a periodic slab with a $\mathrm{p}(3 \mathrm{x} 3)$ unit cell of five Pd layers and a vacuum regions of $10 \AA$ A. A 7x7x1 Monkhorst-Pack $k$ points mesh was employed for the Brillouin zone integration together with a second order Methfessel- 
Paxton smearing method ${ }^{57}$ with a sigma of $0.2 \mathrm{eV}$. Slabs were cut from the optimized Pd bulk unit cell with a lattice constant of $\mathrm{a}=3.94 \AA$ which overestimates the experimental value of $3.89 \AA$ by $1 \%$. In all geometry optimizations only the top-two Pd monolayers were allowed to relax whereas the bottom three monolayers were kept fixed. All optimizations were carried out to forces below $0.02 \mathrm{eV} / \AA ̊$.

All energies are referenced to the bare Pd slab, ethanol, water and hydrogen in the gas phase. The latter two serve to introduce oxygen atoms and to account for the coupled proton-electron transfers, respectively. In particular, the reaction energies of electrochemical steps (i.e. steps where the number of protons in the system is changing) are computed according to the computational hydrogen electrode, ${ }^{7}$ e.g. the reaction:

$$
\mathrm{CH}_{3} \mathrm{CO}+\mathrm{H}_{2} \mathrm{O} \rightarrow \mathrm{CH}_{3} \mathrm{COOH}+\mathrm{H}^{+}+\mathrm{e}^{-}
$$

is computed as

$$
\mathrm{E}_{\mathrm{rxn}}=\mathrm{E}_{(\mathrm{CH} 3 \mathrm{COOH})}-\left[\mathrm{E}_{(\mathrm{CH} 3 \mathrm{CO})}+\mathrm{E}_{(\mathrm{H} 2 \mathrm{O})}+0.5 \mathrm{E}_{(\mathrm{H} 2)}+\mathrm{U}\right]
$$

Where we have assumed $\mathrm{U}$ to be with respect to the $\mathrm{pH}$ insensitive $\mathrm{RHE}$ and a $\mathrm{pH}$ of 0 . Note that at $\mathrm{pH}=14$, we write the same expression for the reaction energy, but formulate the reaction as

$$
\mathrm{CH}_{3} \mathrm{CO}+\mathrm{OH}^{-} \rightarrow \mathrm{CH}_{3} \mathrm{COOH}+\mathrm{e}^{-}
$$

Similarly, we write

$$
\mathrm{CH}_{3} \mathrm{CHO}+\mathrm{OH}^{-} \rightarrow \mathrm{CH}_{3} \mathrm{CO}+\mathrm{H}_{2} \mathrm{O}+\mathrm{e}^{-}
$$

in alkaline conditions and compute the reaction energy $\left(\mathrm{E}_{\mathrm{rxx}}\right)$ as

$$
\mathrm{E}_{\mathrm{rxn}}=\mathrm{E}_{(\mathrm{CH} 3 \mathrm{CO})}-\left[\mathrm{E}_{(\mathrm{CH} 3 \mathrm{CHO})}+0.5 * \mathrm{E}_{(\mathrm{H} 2)}+\mathrm{U}\right]
$$

The transition states (TS) have been located as follows: the state with the $\mathrm{C}-\mathrm{C}$ bond broken was constructed in analogy to the adsorption mode of the individual fragments. This co-adsorbed state was optimized in order to ensure that no significant lateral interactions were introduced. Then, a rough nudged-elastic band $(\mathrm{NEB})^{58}$ computation with 8 images between the initial and final state was 
performed, seeded by interpolations between the two states obtained by Opt'n Path code ${ }^{59}$ which uses a combination of internal and Cartesian coordinates. After about 50 cycles of NEB, an improved guess for the transition state was obtained, which was refined by the dimer method ${ }^{60}$ and verified to be a first order saddle point by a frequency analysis.

Infrared spectra of surface species were modeled following the same procedure, the intensities being evaluated using density functional perturbation theory. ${ }^{61}$ Infrared spectra of solution species were computed using the same DFT functional (PBE) combined with a continuum model for the water solvent $(\mathrm{PCM})^{62}$ with a def2-TZVP basis set using the Gaussian09 version D.01 program. ${ }^{63}$

\section{Results and discussion}

\subsection{Pd/C Nanoparticles characterization and electrochemical performance}

The physical, structural, and chemical characterizations of $\mathrm{Pd} / \mathrm{C}$ are shown in Figure S1; other details have been published elsewhere. ${ }^{49}$ In summary, the supported particle size was determined to be on average $4 \pm 2 \mathrm{~nm}$. The XRD pattern showed that the nanoparticles retained the face-centered-cubic (fcc) structure of bulk Pd with peaks at 40, 46 and $68^{\circ} 2 \theta$ corresponding to (111), (200) and (220) reflections, respectively.

Cyclic voltammetry was used to determine ethanol oxidation current/potential profiles for $\mathrm{Pd} / \mathrm{C}$ nanoparticles in alkaline conditions as shown in Figure 1b. Figure $1 \mathrm{~b}$ shows a representative $\mathrm{CV}$ of $\mathrm{Pd} / \mathrm{C}$ nanoparticles in $1 \mathrm{M}\left(\mathrm{KOH}+\mathrm{CH}_{3} \mathrm{CH}_{2} \mathrm{OH}\right)$ and $1 \mathrm{M}\left(\mathrm{KOH}+\mathrm{CH}_{3} \mathrm{COOH}\right)$ solutions at $5 \mathrm{mV} \mathrm{s}^{-1}$. The slow scanning rate helps to capture the oxidation profile with current densities close to a steady-state condition. For ethanol profile, during the anodic scan, a positive current starts at $0.39 \mathrm{~V}$ and increases gradually to a maximum current density at $0.77 \mathrm{~V}$, and then decreases to zero at $1.00 \mathrm{~V}$. During the cathodic scan, a positive current was obtained starting at $0.76 \mathrm{~V}$, which increases rapidly to a maximum 
at $0.66 \mathrm{~V}$, and then decreases to zero at $0.39 \mathrm{~V}$. The $\mathrm{CV}$ profile for acetic acid did not show any oxidation current densities, a prove that the resulting acetate $\left(\mathrm{KOH}+\mathrm{CH}_{3} \mathrm{COOH}\right)$ is the dead end during ethanol electrooxidation reaction.

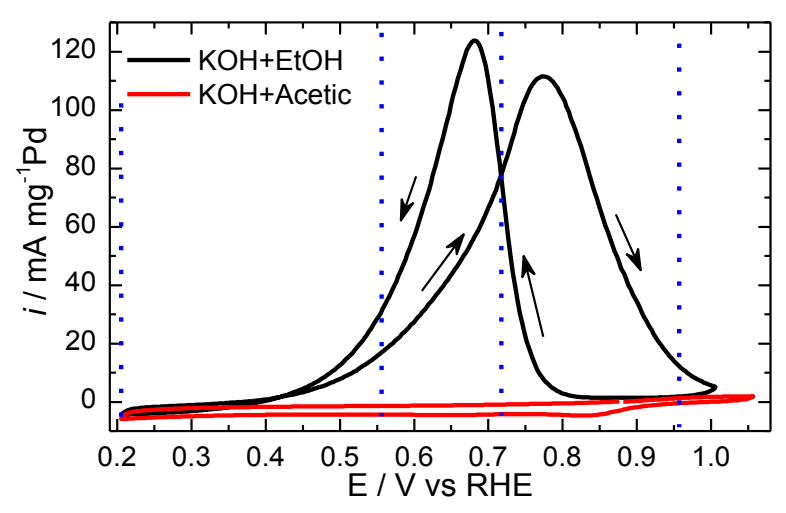

(a)

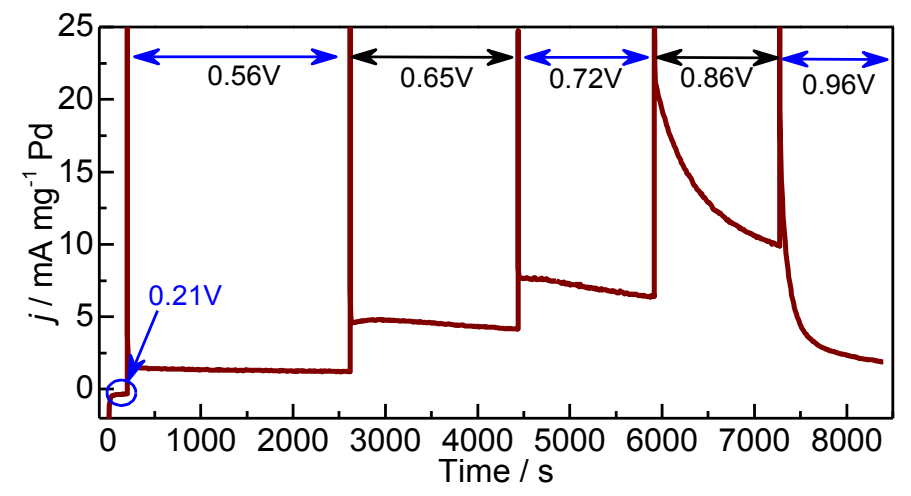

(b)

Figure 1. The $\mathrm{CV}$ profile for $\mathrm{Pd} / \mathrm{C}$ nanoparticles in $1 \mathrm{M}(\mathrm{KOH}+\mathrm{EtOH})$ and $1 \mathrm{M}(\mathrm{KOH}+\mathrm{Acetic})$ at $\mathrm{v}=5$ $\mathrm{mV} \mathrm{s}^{-1}(\mathrm{a})$, and the $\mathrm{CA}$ profile of $\mathrm{Pd} / \mathrm{C}$ nanoparticles in $1 \mathrm{M}(\mathrm{KOH}+\mathrm{EtOH})$ at various potentials as indicated by the double arrows (b). The vertical lines and double arrows (colored blue) shows the potentials whose PM-IRRAS spectra are discussed in the text.

This ethanol electrooxidation profile (Figure 1b) is typical for alcohols and is generally interpreted as a signature of species blocking the electrocatalyst surface at higher potential that can be removed while scanning back to lower potentials hence allowing oxidation of fresh ethanol molecules. ${ }^{19,64,65}$ To gain insights of the processes taking place at different potentials of the $\mathrm{CV}$ profile, chronoamperometry coupled with PM-IRRAS were used and the resulting data is discussed in the following section.

\subsection{Identification of ethanol electrooxidation products on $\mathrm{Pd} / \mathrm{C}$ surface and in the bulk electrolyte solution}

Chronoamperometry measurements were coupled with in-situ polarization-modulation infrared reflection absorption spectroscopy (PM-IRRAS) to identify ethanol electrooxidation products at different potentials. Figure $1 \mathrm{~b}$ shows the resulting current/potential CA response, in which the potential was stepped up from $0.21 \mathrm{~V} / \mathrm{RHE}$ to $0.96 \mathrm{~V} / \mathrm{RHE}$ while collecting spectra at each potential in 
increments of 5 minutes up to 30 minutes. The spectra collected at $0.21,0.56,0.72$, and $0.96 \mathrm{~V} / \mathrm{RH}$ are shown in Figure 2(a)-(h). As presented above and in the SI, the PM-IRRAS unlike the regular IRRAS technique allows us to distinguish between the oxidation species on/near the electrode surface (using the difference absorption intensities of $\mathrm{p}$ - and s-polarized reflection) and the oxidation species in the bulk/liquid-phase electrolyte within the thin-cavity between the $\mathrm{CaF}_{2}$ window and the electrode (using the average absorption intensities of p- and s-polarized reflection). Herein, the spectra for the species on the electrode surface and spectra of the sum species in the thin-cavity will be referred to as "surface" and "bulk solution" species, respectively. ${ }^{66}$

Prior to the measurement of ethanol electrooxidation species spectra, it is important to ensure that there is no atmospheric $\mathrm{CO}_{2}$ and water vapor in the optical path which would not only decrease the IR intensity but also would contribute to observed spectra features. Especially the presence of $\mathrm{CO}_{2}$ is critical because it is one of the anticipated ethanol oxidation products. This objective was accomplished by purging the electrolyte and the cell chamber (PMA 50) with nitrogen gas and the level of $\mathrm{CO}_{2}$ in the system was tracked by collecting a series of background PM-IRRAS spectra at open circuit potential i.e. no applied potential. Figure S7 shows the background surface and bulk species spectra collected at various time intervals. The first spectrum (Figure S7 curve(s) (a)) was collected at the beginning of the experiment i.e. 2.5 hours before actual measurements were started. Two other spectra were collected at 30 minutes Figure S7 curve (b) and at 3 minutes Figure S7 curve (c) before the actual measurements were done. In summary, it was determined that after 2.5 hours there was no significant background contribution to interfere with any spectra features as confirmed by the straight line of Figure S7 curve(s) c). Now we shift our attention to the spectra features obtained at the various potentials as shown in Figure 2. The potentials reported were selected from the different regions of the CV profile (Figure 1a) 
and are meant to shed more insights of the reaction dynamics and/or intermediates/products at those regions.

Figure $2(\mathrm{a} \& \mathrm{~b})$ shows the PM-IRRAS spectra at $0.21 \mathrm{~V} / \mathrm{RHE}$ where there is no ethanol electrooxidation according to $\mathrm{CV}$ and $\mathrm{CA}$ (Figure 1). At this potential we see a negative peak centered around $2908 \mathrm{~cm}^{-1}$ which is due to breaking of the $\mathrm{C}-\mathrm{H}$ bond. There are also two positive peaks centered on $2819 \mathrm{~cm}^{-1}$ and $3668 \mathrm{~cm}^{-1}$ which corresponds to $\mathrm{C}-\mathrm{H}$ and $\mathrm{H}_{2} \mathrm{O}$ vibrations, respectively. These observations tell us that there is some form of re-organization of the electrolyte molecules on the electrode surface. On the other hand, we do not see any significant structural changes features in bulk solution as shown by the straight line in Figure $2 \mathrm{~b}$. This is expected at this low potential.

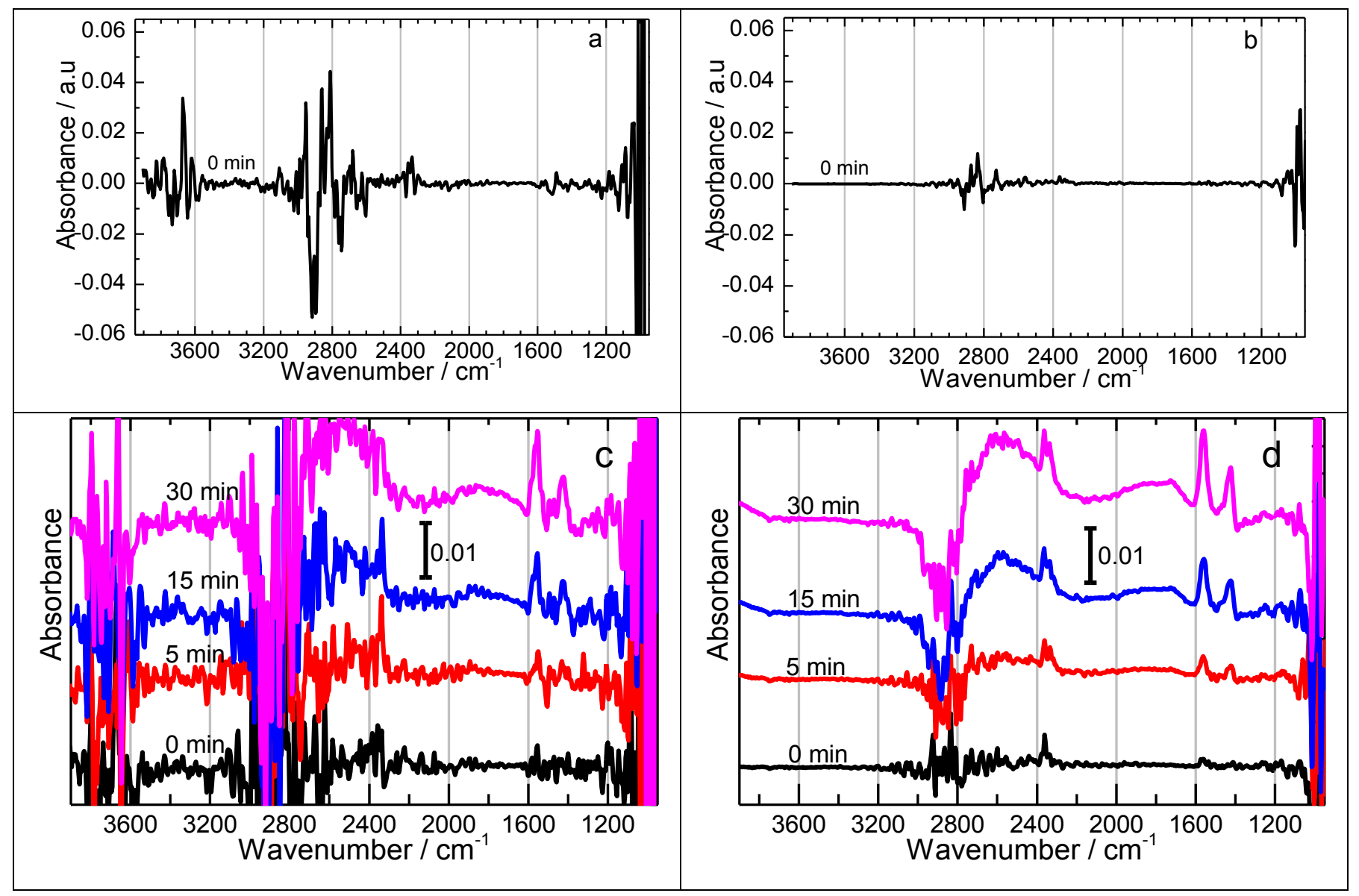




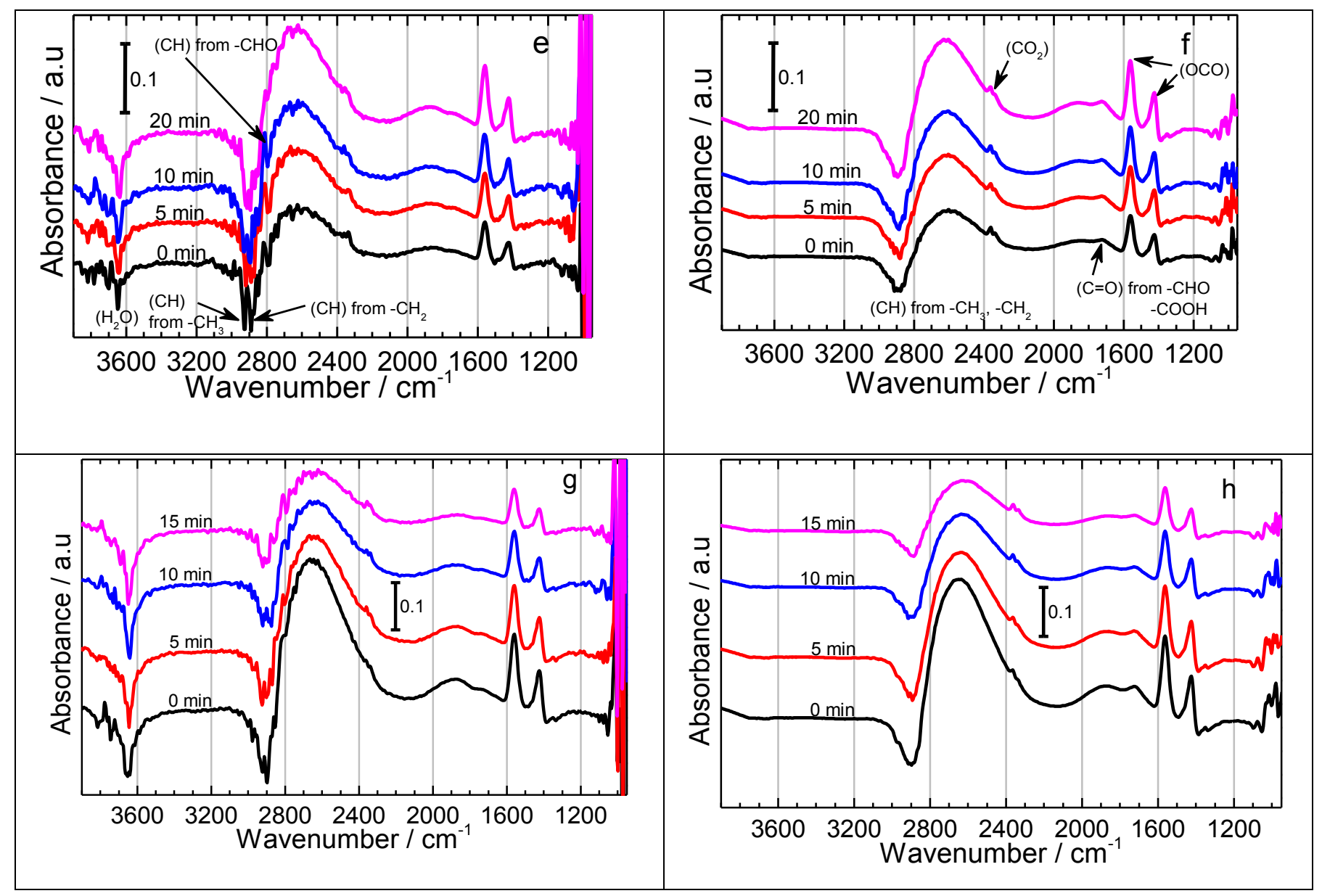

Figure 2. PM-IRRAS spectra for ethanol electrooxidation products on $\mathrm{Pd} / \mathrm{C}$ nanoparticles in $1 \mathrm{M}(\mathrm{KOH}$ $\left.+\mathrm{C}_{2} \mathrm{H}_{5} \mathrm{OH}\right)$ at $0.21 \mathrm{~V}(\mathrm{a}, \mathrm{b}), 0.56 \mathrm{~V}(\mathrm{c}, \mathrm{d}), 0.72(\mathrm{e}, \mathrm{f})$, and $0.96 \mathrm{~V}(\mathrm{~g}, \mathrm{~h})$ vs RHE. The left panels show oxidation species on the surface and the right panels show oxidation species in the thin-cavity/bulk solution. The spectra were processed using equation 3 and the reference spectrum was collected at the open circuit potential, see SI for details. At each potential (row), the y-scale was made the same for easy/direct comparison between surface and bulk species.

Figure 2 (c \& d) shows the surface and bulk solution species at $0.56 \mathrm{~V} / \mathrm{RHE}$, which is closer to the onset potential for ethanol electrooxidation. The surface species spectra look very noise compared with the bulk solution spectra. This phenomenon can be attributed to the dynamic activities taking place on the electrode surface at this potential. Of top interest at this potential, is the evidence of the $\mathrm{C}-\mathrm{C}$ bond cleavage to form $\mathrm{CO}_{2}$ due to the positive peak at $2353 \mathrm{~cm}^{-1}$. With the PM-IRRAS we were even able to distinguish that the produced $\mathrm{CO}_{2}$ quickly desorbs/diffuses into the bulk solution as shown by the 
intensity of the peak. The conversion of $\mathrm{CO}_{2}$ into carbonate was not evident (see Figure S2) in this work probably due to the changing $\mathrm{pH}$ conditions within the thin-cavity from alkaline to neutral/acidic. ${ }^{67}$ One can notice that while the amount of $\mathrm{CO}_{2}$ increases clearly with time at lower potential $(0.56 \mathrm{~V})$, its accumulation is hampered or overshadowed by other species at higher potential. Although, the formation of CO during EOR on Pd in alkaline has been reported,$^{21}$ we do not have evidence to support that argument in our spectra even after SNIFTIR treatment of our data as claimed in ref 21. Our data collaborates well with other similar work in literature where $\mathrm{CO}$ was not observed. ${ }^{12}$ Therefore, the formation of $\mathrm{CO}$ during $\mathrm{C}-\mathrm{C}$ bond cleavage maybe regarded to be a very fast process as it is directly converted to observed $\mathrm{CO}_{2}$ at the lower potentials.

The presence of positive peaks at $1560 \mathrm{~cm}^{-1}$ (strong), $1423 \mathrm{~cm}^{-1}$ (medium), and $1350 \mathrm{~cm}^{-1}$ (weak) on the surface and bulk solution spectra in Figure 2 (c) - (h), corresponds to the asymmetric, symmetric, and $\mathrm{C}-\mathrm{H}$ bending vibrations from the acetate $\left(\mathrm{CH}_{3} \mathrm{COO}^{-}\right)$produced during ethanol electrooxidation in agreement with other literature reports. ${ }^{19,21,68}$ These peak assignments were confirmed with transmission infrared spectroscopy as shown in Figure S2 and the use DFT simulations as reported in Table 1. The simulated spectra in solution (continuum model) show the same three peaks $\left(1558 \mathrm{~cm}^{-1} ; 1410 \mathrm{~cm}^{-1} ; 1334\right.$ $\left.\mathrm{cm}^{-1}\right)$. The strongest peak is also the one at $1558 \mathrm{~cm}^{-1}$ and corresponds to the asymmetric $\mathrm{COO}^{-}$ vibrations. The corresponding symmetric mode vibrates at $1334 \mathrm{~cm}^{-1}$ and has the second highest intensity. Finally, the peak around $1410 \mathrm{~cm}^{-1}$ corresponds to bending modes of the $\mathrm{CH}_{3}$ group and features only a weak intensity. The relative positioning of the weak $\mathrm{C}-\mathrm{H}$ bending and strong $\mathrm{COO}^{-}$ symmetric stretch are inverted in the DFT computations compared to experiment. This has already been reported in the literature. ${ }^{69}$ Depending on the functional, ${ }^{70}$ the $\mathrm{C}-\mathrm{H}$ bending and symmetric $\mathrm{COO}$ stretching frequencies are more or less mixed, leading to intensity redistributions between the $\mathrm{C}-\mathrm{H}$ and COO modes, suggesting that anharmonicity should be accounted for. Due to the very high 
computational cost of such a treatment, this is, however, beyond the scope of this paper. The $\mathrm{COO}^{-}$ symmetric stretch is red-shifted in our computations by about $100 \mathrm{~cm}^{-1}$.

Table 1. Normal modes (in $\mathrm{cm}^{-1}$ ) for acetate in the region 1200-1600 $\mathrm{cm}^{-1}$ (i) as obtained experimentally (see Figure S3) (ii) as computed as a function of the number of water molecules that solvate the COOmoiety in solution (iii) as computed for $\mathrm{CH}_{3} \mathrm{COO}$ adsorbed on a $\mathrm{Pd}(100)$ slab.

\begin{tabular}{llllcll}
\hline & Species & COO $_{\text {Sym }}$ & $\mathbf{C H}$ & $\mathbf{C H}$ & $\mathbf{C O O}_{\text {Asym }}^{-}$ & $\begin{array}{l}\text { Splitting/cm } \\
\text { 1 }\end{array}$ \\
\hline (i) & $\mathbf{C H}_{3} \mathbf{C O O}$, exp & 1423 & & 1346 & 1560 & 137 \\
(ii) & $\mathrm{CH}_{3} \mathrm{COO}$ & 1334 & 1400 & 1417 & 1558 & 224 \\
(ii) & $\mathrm{CH}_{3} \mathrm{COO}, \mathrm{H}_{2} \mathrm{O}$ & 1337 & 1403 & 1417 & 1541 & 204 \\
(ii) & $\mathrm{CH}_{3} \mathrm{COO}, 2 \mathrm{H}_{2} \mathrm{O}$ & 1353 & 1402 & 1418 & 1534 & 181 \\
(ii) & $\mathrm{CH}_{3} \mathrm{COO}, 3 \mathrm{H}_{2} \mathrm{O}$ & 1353 & 1398 & 1416 & 1524 & 171 \\
(iii) & $\mathrm{CH}_{3} \mathrm{COO} @ \mathrm{Pd}(100)$ & 1360 & 1408 & 1430 & 1477 & 117 \\
\hline
\end{tabular}

The inclusion of explicit water (see Table 1) mainly affects the $\mathrm{COO}^{-}$stretch vibrations, with the asymmetric and symmetric mode being red- and blue-shifted by 30 and $20 \mathrm{~cm}^{-1}$, respectively. This improves the mode splitting from 224 to $171 \mathrm{~cm}^{-1}$ compared to the experimental $137 \mathrm{~cm}^{-1}$. From Table 1, it is noticeable that the infrared spectrum of $\mathrm{CH}_{3} \mathrm{COO}$ adsorbed on a $\mathrm{Pd}(100)$, the asymmetric vibration is also red-shifted by $80 \mathrm{~cm}^{-1}$ compared to the one of $\mathrm{CH}_{3} \mathrm{COO}$ using a continuum model for the water solvent. In addition, the two other peaks are much weaker than in solution. Thus, the comparison of the DFT simulations and the PM-IRRAS spectra shows that the "surface" species signal obtained experimentally corresponds mainly to solvated species in the interfacial water zone.

There is a remarkable difference between surface species and bulk solution species in the regions 1620 $-2000 \mathrm{~cm}^{-1}$, and $3648 \mathrm{~cm}^{-1}$ which also highlights the utility of PM-IRRAS technique. It is evident that the species absorbing at $1726 \mathrm{~cm}^{-1}$ is mainly available in the bulk solution but not on/or near the electrode surface. This peak corresponds to $\mathrm{C}=\mathrm{O}$ stretching vibrations of an aldehyde/ketone or acetic acid. Our DFT simulations for acetaldehyde show a strong peak at $1720 \mathrm{~cm}^{-1}(\mathrm{C}=\mathrm{O})$ but also two weak peaks between $1300-1400 \mathrm{~cm}^{-1}(\mathrm{C}-\mathrm{H}$ bending), overlapping with the weaker peaks of acetate and one 
strong peak at $2812 \mathrm{~cm}^{-1}\left(\mathrm{C}-\mathrm{H}\right.$ stretch), overlapping also with a broad band centered around $2600 \mathrm{~cm}^{-1}$. The origin of the broad peak at $2600 \mathrm{~cm}^{-1}$ would be due to accumulation of combination of various intermediates (ethoxy, acetaldehyde \& its hydrate form, and acetic acid) in the thin-cavity as shown in Figure S3. Figure S3a shows the simulated spectra for ethoxy $\left(\mathrm{CH}_{3} \mathrm{CH}_{2} \mathrm{O}\right)$, acetaldehyde $\left(\mathrm{CH}_{3} \mathrm{CHO}\right)$, hydrated acetaldehyde $\left(\mathrm{CH}_{3} \mathrm{CHOOH}\right)$, and acetic acid $\left(\mathrm{CH}_{3} \mathrm{COOH}\right)$, which confirms that ethoxy and hydrated acetaldehyde have bands near $2600 \mathrm{~cm}^{-1}$. Although, the simulated spectrum for acetic acid [Figure S3 (a)] does not show any peak between $2400 \mathrm{~cm}^{-1}$ and $2700 \mathrm{~cm}^{-1}$, the experimental spectrum [Figure S3 (b)] shows that acetic acid has three overlapping peaks within the region. Therefore, the potential candidates for the broad peak at $2400-2700 \mathrm{~cm}^{-1}$ would be ascribed to a combination of ethoxy, geminal-diol, and acetic acid as a result of the changing $\mathrm{pH}$ during the electrooxidation. Further studies are underway to confirm the true origin of this broad peak centered on $2600 \mathrm{~cm}^{-1}$. The absence of the peak at $1726 \mathrm{~cm}^{-1}$ on the surface spectra is probably due to the low concentration of acetaldehyde and/or its interaction with the electrode surface. The negative peak at $3648 \mathrm{~cm}^{-1}$ on the surface species spectra is the evidence for the consumed water molecules at the electrode surface. Note that at higher potential i.e. $0.96 \mathrm{~V}$, where the catalyst surface is deactivated, the products accumulation decreases with time but no evidence for the formation of $\mathrm{CO}_{2}$. This observation proves that acetate is indeed the dead end for EOR in agreement with the acetate CV in Figure 1 (a). Therefore, the cleavage of $\mathrm{C}-\mathrm{C}$ bond is only possible at lower potentials.

To sum up, the PM-IRRAS spectra show that at lower potential it is possible to break the $\mathrm{C}-\mathrm{C}$ bond of ethanol on $\mathrm{Pd} / \mathrm{C}$ in alkaline media to form $\mathrm{CO}_{2}$. However, the selectivity is poor due to competition towards the formation of acetate, which gets worse at higher potentials. In addition, traces of acetaldehyde are found in the bulk solution. Based on these experimental insights, we now explore the 
most likely intermediates involved in the reaction path using DFT calculations as presented in the next sections.

\subsection{Reaction mechanism}

The reaction network involved in ethanol electro-oxidation is quite complex as presented above, even after simplifying it by considering only proton coupled electron transfers as electrochemical steps. There are 12 electrons to be recovered through 9 proton abstractions and $3 \mathrm{OH}$ additions. Our simulations do not include explicitly the influence of the water-based electrolyte on the intermediates structures. However, the main determining factor is the role of $\mathrm{OH}^{-}$as a proton acceptor on the thermochemistry, and this is included in the computational hydrogen electrode approach.

Furthermore, the reaction only proceeds to completion if the $\mathrm{C}-\mathrm{C}$ bond can be broken. Hence, we need at least to consider the following elementary reaction steps, with specific examples given for illustration in equations (10) - (13):

$$
\begin{array}{ll}
\mathrm{C}-\mathrm{H} \text { scission: } & \mathrm{CH}_{3} \mathrm{CH}_{2} \mathrm{OH} @ \mathrm{Pd}+\mathrm{OH}^{-} \rightarrow \mathrm{CH}_{3} \mathrm{CHOH} @ \mathrm{Pd}+\mathrm{e}-+\mathrm{H}_{2} \mathrm{O} \\
\mathrm{O}-\mathrm{H} \text { scission: } & \mathrm{CH}_{3} \mathrm{CH}_{2} \mathrm{OH} @ \mathrm{Pd}+\mathrm{OH}^{-} \rightarrow \mathrm{CH}_{3} \mathrm{CH}_{2} \mathrm{O} @ \mathrm{Pd}+\mathrm{e}-+\mathrm{H}_{2} \mathrm{O} \\
\mathrm{C}-\mathrm{OH} \text { formation: } & \mathrm{CH}_{3} \mathrm{CHOH} @ \mathrm{Pd}+\mathrm{OH}^{-} \rightarrow \mathrm{CH}_{3} \mathrm{CH}(\mathrm{OH})_{2} @ \mathrm{Pd}+\mathrm{e}- \\
\mathrm{C}-\mathrm{C} \text { scission: } & \mathrm{CH}_{3} \mathrm{CH}_{2} \mathrm{OH} @ \mathrm{Pd}+\mathrm{Pd} \rightarrow \mathrm{CH}_{3} @ \mathrm{Pd}+\mathrm{CH}_{2} \mathrm{OH} @ \mathrm{Pd}
\end{array}
$$

To break up the complexity into smaller manageable parts, we proceed as follows: PM-IRRAS data demonstrates that the electrooxidation of ethanol over Pd leads to identifiable acetate and traces of $\mathrm{CO}_{2}$. Therefore, for simplicity, we start by studying the intermediates that lead to acetate on the dominant $\operatorname{Pd}(111)$ and the more reactive and still sufficiently abundant $\operatorname{Pd}(100)$ surface. A brief description of the geometric features can be found in SI, we discuss here their relative energies and the most likely reaction pathway until acetate. Then, in order to obtain a "complete" picture, we have searched the most stable $\mathrm{C}_{1}$ and $\mathrm{C}_{2}$ intermediates at each oxidation state until $\mathrm{CO}_{2}$. Based on this overview, we shed more 
light on the reason why the reaction stops at the acetate level and why the selective cleavage of the $\mathrm{C}-$ $\mathrm{C}$ bond is difficult.

\subsubsection{From ethanol to acetate}

Pd(111): Figure S8 shows the adsorption structures of the most important intermediates involved in ethanol electrooxidation on $\operatorname{Pd}(111)$. The structures are in line with the literature ${ }^{71}$ and thus we focus here on the relative energies of the intermediates at a given oxidation state and their involvement in the oxidation path towards acetic acid. Figure 3 (a) shows the reaction energy profile for ethanol oxidation on $\mathrm{Pd}(111)$ at a potential of $0.26 \mathrm{~V}$, based on the computational hydrogen electrode ${ }^{7}$ (see Computational Details). This potential corresponds to the thermodynamic equilibrium potential for the oxidation of ethanol to $\mathrm{CO}_{2}$. In reality, over-potentials are necessarily observed but with only $0.4 \mathrm{~V}, \mathrm{Pd}$ is rather promising in terms of onset potentials. Each column in the reaction coordinate corresponds to intermediates at a given oxidation state. Intermediates below and above the dotted line are due to exothermic and endothermic processes, respectively.

The ethoxy $\left(\mathrm{CH}_{3} \mathrm{CH}_{2} \mathrm{O}\right)$ species is higher in energy than the $\alpha$-dehydrogenated intermediate $\mathrm{CH}_{3} \mathrm{CHOH}$ in agreement with previous reports. ${ }^{71}$ However, Hibbits and Neurok ${ }^{30}$ have modelled the oxidation of EtOH by $\mathrm{O}_{2}$ in which the catalyst surface was pre-covered with $\mathrm{O}$ and $\mathrm{OH}$ species and have shown that the formation of ethoxy has the lowest activation barrier in these conditions, proving that it is an important intermediate. The $\mathrm{CH}_{2} \mathrm{CH}_{2} \mathrm{OH}$ is intermediate in energy. A second proton coupled electron transfer leads to an oxidation state which is particularly challenging to describe realistically: three adsorbed intermediates are connected through well-known solution equilibria: acetaldehyde, its hydrate (the geminal diol) and the enol; the forth intermediate considered $\left(\mathrm{CH}_{3} \mathrm{COH}\right)$ is strongly bound to the metal surface and can only indirectly participate in the equilibrium. 


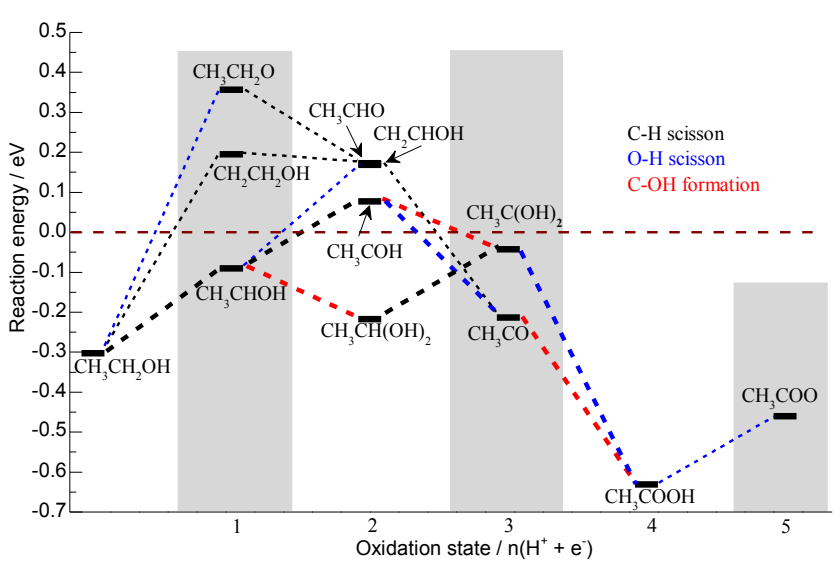

(a) $\operatorname{Pd}(111)$

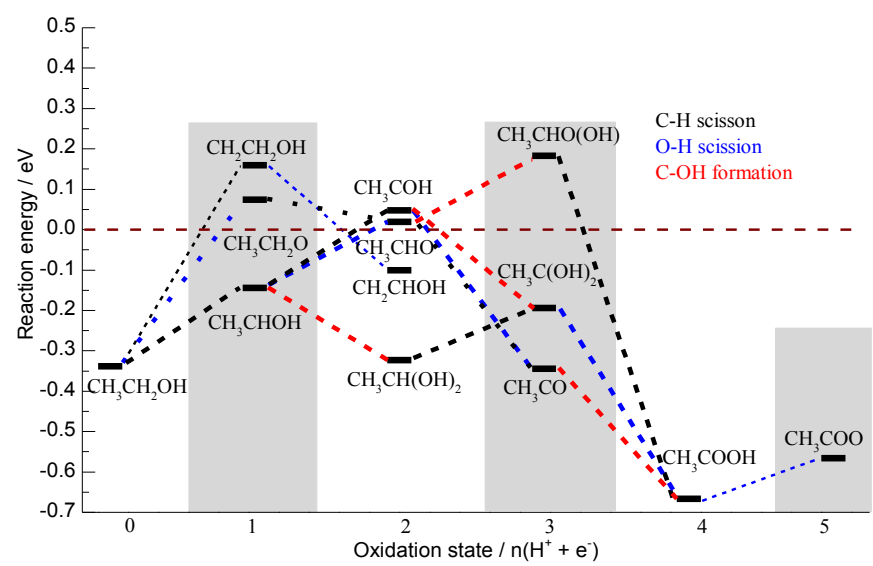

(b) $\operatorname{Pd}(100)$

Figure 3. Reaction energy profile for ethanol oxidation on (a) $\operatorname{Pd}(111)$ surface and (b) $\operatorname{Pd}(100)$ surface at a potential of $0.26 \mathrm{~V}$ vs RHE. Only the most important (and low lying) intermediates are shown. The dotted line connecting the intermediates are color coded according to the reaction process taking place, black and blue correspond to $\mathrm{C}-\mathrm{H}$ and $\mathrm{O}-\mathrm{H}$ bond scission, respectively while red corresponds to $\mathrm{C}-$ $\mathrm{O}$ bond formation

On the surface, acetaldehyde and its enol are almost iso-energetic. Since the $\mathrm{CH}_{2} \mathrm{C}_{\mathrm{x}}$ intermediates at the following oxidation states are significantly higher in energy than the $\mathrm{CH}_{3} \mathrm{C}_{\mathrm{x}}$ intermediates, we consider the enol to be a dead end, i.e., it just participates in the equilibria if formed. In fact, it is rather the hydrate which is the dominant intermediate: it is the lowest energy intermediate, is connected to the previous lowest energy intermediate and can form either in solution through acetaldehyde or on the surface by a surface $\mathrm{OH}$ assisted process.

The oxidation of the hydrate does not lead to the lowest energy intermediate at oxidation state +3 . The lowest energy intermediate at oxidation state +3 is the acetyl $\left(\mathrm{CH}_{3} \mathrm{CO}\right)$ and it is only accessible from higher energy intermediates of the previous oxidation state +2 . Oxidation of $\mathrm{CH}_{3} \mathrm{CO}$ or $\mathrm{CH}_{3} \mathrm{C}(\mathrm{OH})_{2}$ invariably yields acetic acid, through a $\mathrm{OH}$ addition and a dehydrogenation, respectively. Acetic acid is by far the lowest energy intermediate on the surface at oxidation state +4 (the second lowest fragment is $\mathrm{CH}_{2} \mathrm{CO}$ at $0.86 \mathrm{eV}$ higher in energy), and can desorb easily into solution. Then, in alkaline solution the 
formation of $\mathrm{CH}_{3} \mathrm{COO}^{-}$is straightforward. This reaction network explains satisfactorily the observed formation of acetic acid (or acetate at high $\mathrm{pH}$ values). After a quick comparison of the acetic acid formation on the $\mathrm{Pd}(100)$ surface, the following sections investigate the prospects to split the $\mathrm{C}-\mathrm{C}$ bond in ethanol.

Pd(100): Figure S9 shows the adsorption structures of the most important intermediates involved in ethanol electrooxidation on $\operatorname{Pd}(100)$. The geometry of the adsorbates is very similar to that on $\operatorname{Pd}(111)$ and is therefore not discussed any further.

Figure 3 (b) shows the reaction energy profile for ethanol electrooxidation on $\operatorname{Pd}(100)$ surface at a potential of $0.26 \mathrm{~V}$. Here we highlight the differences between $\operatorname{Pd}(100)$ surface and $\operatorname{Pd}(111)$. One difference is that the reaction energies are shifted to lower energies by ca. $0.1-0.2 \mathrm{eV}$, meaning that the (100) surface is more reactive than the (111) surface in agreement with previous reports. ${ }^{72,73,74}$ The second difference is that the relative stability of acetaldehyde $\left(\mathrm{CH}_{3} \mathrm{CHO}\right)$ and 1-hydroxyethylidene $\left(\mathrm{CH}_{3} \mathrm{COH}\right)$ is reversed: on the 100 surface, $\mathrm{CH}_{3} \mathrm{CHO}$ is $0.02 \mathrm{eV}$ more stable than $\mathrm{CH}_{3} \mathrm{COH}$. However, it is doubtful that these very small energy differences are representative of the situation under electrocatalytic conditions where the solvent and the potential may easily change the relative energies by more than this difference. In any case, the geminal-diol is the lowest intermediate at this oxidation state for both surfaces. Therefore, we can conclude that investigating the $\operatorname{Pd}(100)$ or $\operatorname{Pd}(111)$ surface is qualitatively the same. Nevertheless, since the (100) surface is more active for bond formation and splitting reactions,$^{74}$ and these reactions are key and highly activated on this surface (vide infra), we report only the results for $\mathrm{Pd}(100)$ in the remainder of this article. Based on our DFT results, we can also predict the overpotential to produce $\mathrm{CH}_{3} \mathrm{COOH}$ from EtOH on Pd catalysts and this overpotential is in agreement with the onset potential observed experimentally. The lowest energy path is represented at various potentials in Figure 4. It starts with the generation of $\mathrm{CH}_{3} \mathrm{CHOH}$, an endothermic step at $0.26 \mathrm{~V}$. 
It yields the gem-diol $\mathrm{CH}_{3} \mathrm{CH}(\mathrm{OH})_{2}$ at the degree of oxidation +3 that is further dehydrogenated into $\mathrm{CH}_{3} \mathrm{C}(\mathrm{OH})_{2}$, a step that is also endothermic at this potential. The last step is strongly exothermic and gives $\mathrm{CH}_{3} \mathrm{COOH}$. At $0.45 \mathrm{~V}$, all the steps along the most stable path to $\mathrm{CH}_{3} \mathrm{COO}^{-}$are predicted being endothermic. At that potential, even the generation of acetaldehyde starts to be exothermic. Those potentials are in line with our experimental results (CV in Figure 1 and the PM-IRRAS spectra in Figure 2) where the reaction starts at around $0.45 \mathrm{~V}$ and where traces of acetaldehyde are identified at 0.65 V/RHE and more intense at $0.72 \mathrm{~V}$.

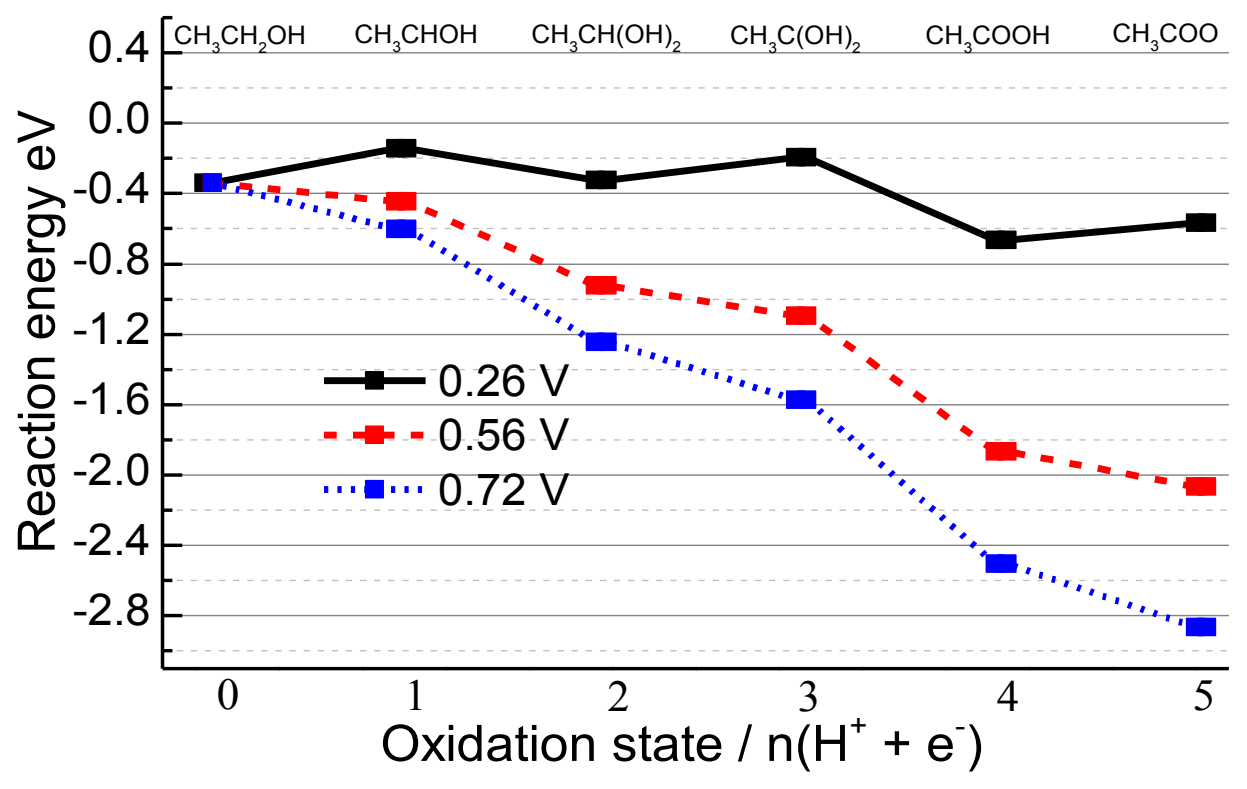

Figure 4. Reaction energy profiles for ethanol electrooxidation on $\operatorname{Pd}(100)$ surface showing the effect of the electrochemical potential $(0.26 \mathrm{~V}, 0.56 \mathrm{~V}$, and $0.72 \mathrm{~V}$ vs RHE) for the most likely C2 reaction path.

\subsubsection{Intermediates beyond Acetate and Breaking the $\mathrm{C}-\mathrm{C}$ bond}

The chemical viability of DEFCs relies on two related aspects. First, the fuel needs to be completely oxidized in order to obtain a realistically useful energy and current density. In other words, catalysts oxidizing ethanol to acetate (acetic acid in acidic media) are not useful in practice, as they would liberate only 4 out of 12 possible electrons. Second, the kinetics needs to be efficient at a reasonably low overpotential. According to the Butler-Volmer equation, a proton coupled electron transfer is directly 
accelerated by the over-potential. Furthermore, the barriers for formal dehydrogenation reactions are fairly small on $\mathrm{Pd}$ (in the order of $0.7 \mathrm{eV}$ ). While the $\mathrm{C}-\mathrm{OH}$ formation could be somewhat more activated, it can equally be considered an electrochemical step and therefore its barrier is likely to be heavily lowered by the over-potential and the presence of surface hydroxyls. If the C-C dissociation were coupled with the formation of the $\mathrm{C}-\mathrm{OH}$ bond, in a concerted mechanism with the hydroxide anion attacking from the solvent, this dissociation would also strongly depend on the electrochemical potential. However, modeling such a process would required a full description of the solvent and a complete inclusion of the electrochemical potential, which is out of the scope of this study. The direct $\mathrm{C}-\mathrm{C}$ bond splitting, in contrast, is a chemical step and thus hardly affected by the electrochemical potential as extrapolated from our findings for the electro-carboxylation of ethene. ${ }^{75}$ Hence, investigating the feasibility of $\mathrm{C}-\mathrm{C}$ bond splitting is key in order to understand both, incomplete oxidation and sluggish kinetics and this can be done without the inclusion of the electrochemical potential.

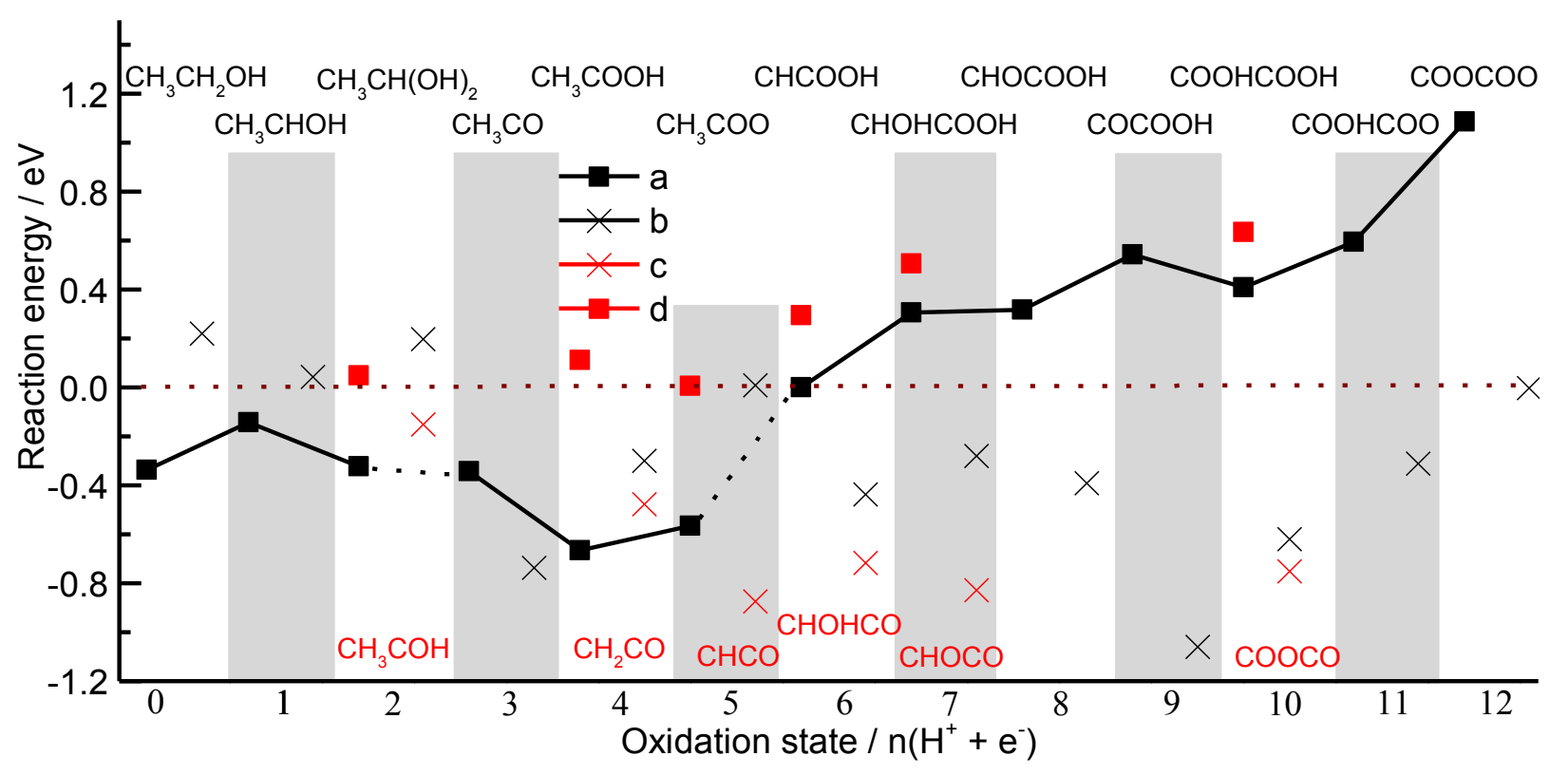


Figure 5. Global reaction energy profile of the most stable intermediates during ethanol electrooxidation process on $\mathrm{Pd}(100)$ at $0.26 \mathrm{~V} / \mathrm{RHE}$. The black squares show the most stable $\mathrm{C} 2$ intermediates at each oxidation state $\left(\mathrm{C}_{2}\right.$ path) whose intermediates are indicated at the top. To guide the eyes, a line has been added, in solid (resp. dotted) when the intermediates are connected (resp. not) from one oxidation state to the next. Legend: (a) Most stable C2 species, (b) C1 fragments generated from the most stable C2, (c) Most stable C1 fragments, and (d) Parent C2 species of the most stable C1 fragments which are shown at the bottom.

Let us start by addressing the first question: which is the most likely possible path that would lead from ethanol to $\mathrm{CO}_{2}$ instead of acetic acid based on thermodynamics? Figure 5 summarizes our effort to identify the lowest energy intermediates at each of the 12 oxidation states, accounting for $\mathrm{C}-\mathrm{H}, \mathrm{O}-\mathrm{H}$ and $\mathrm{C}-\mathrm{C}$ bond activations as well as $\mathrm{C}-\mathrm{OH}$ bond formation. The intermediates below the zero horizontal dashed line in Figure $\mathbf{5}$ are due to an exothermic process while those above the line are due to an endothermic process at the potential of $0.26 \mathrm{~V}$ i.e. the minimum potential for which ethanol oxidation is energetically feasible in terms of free energy. At each oxidation state we indicate the most stable $\mathrm{C}_{2}$ intermediate and the energy of its $\mathrm{C}-\mathrm{C}$ bond broken $\mathrm{C}_{1}$ analogue. Of course, at any given oxidation step, the lowest intermediate before the $\mathrm{C}-\mathrm{C}$ bond breaking does not need to yield the lowest two $\mathrm{C}_{1}$ fragments at that oxidation step, which is indicated by the presence of open circles on Figure 5. Note that we did not consider additional "pure" chemical steps which further complicate the reaction network, e.g. by introducing formic acid $(\mathrm{HCOOH})$ at the same oxidation state as $\mathrm{CO}$. Similarly, the lowest energy intermediate at each oxidation state " $n$ " is not necessarily directly related to the intermediate of oxidation state "n+1" (e.g., $\mathrm{CH}_{3} \mathrm{CH}_{2}(\mathrm{OH})_{2}$ is the most stable intermediate at oxidation state +2 , but at +3 , it is $\mathrm{CH}_{3} \mathrm{CO}$ ), which is indicated by broken black lines instead of the full lines.

As mentioned in the introduction, ethanol electrooxidation mechanism is best presented in a "dual path mechanism scheme". The $\mathrm{C}_{2}$ path does not involve the breaking of the $\mathrm{C}-\mathrm{C}$ bond while in the $\mathrm{C}_{1}$ the $\mathrm{C}-\mathrm{C}$ bond yielding $\mathrm{C}_{1}$ fragments. In agreement with previous reports, ${ }^{31}$ we found a reasonably wellconnected $\mathrm{C}_{2}$ pathway up to $\mathrm{CH}_{3} \mathrm{COO}(+5)$. However, from +5 to +6 , the lowest energy intermediate 
changes dramatically from $\mathrm{CH}_{3} \mathrm{COO}$ to $\mathrm{CHCOOH}$. Furthermore, the process is endothermic by $0.6 \mathrm{eV}$ at the thermodynamic equilibrium potential for the overall reaction. This implies that a potential of at least $0.6 \mathrm{~V}$ would be necessary to drive the oxidation beyond acetate (acetic acid). The fact that these intermediates are not connected would mean a further increase of the over-potential. This is in agreement with the cyclic voltammetry experiments demonstrating that acetic acid is inert for further oxidation, i.e. no current transfer was observed in the $\mathrm{CVs}$ with $1 \mathrm{M}\left(\mathrm{KOH}+\mathrm{CH}_{3} \mathrm{COOH}\right)$ solution as shown in Figure 1. To conclude, Figure 5 indicates that it would be ideal to split the $\mathrm{C}-\mathrm{C}$ bond before reaching acetate (acetic acid in acid media), which is the dead end of the reaction with the current catalysts. On the other hand, on thermodynamic grounds, the $\mathrm{C}-\mathrm{C}$ bond splitting is "constantly" beneficial from oxidation state +6 onwards and, in general, passing to the $C_{1}$ pathway is more likely when the $\mathrm{C}_{2}$ fragment can be split through a de-carbonylation, generating a highly stable $\mathrm{CO}$ moiety.

Turning to the second limitation, i.e., the sluggish kinetics, we investigate the reasons for which the $\mathrm{C}$ - C bond is not split before reaching acetic acid. Both for ethanol and for the first oxidative intermediate, the $\mathrm{C}-\mathrm{C}$ bond breaking is highly unlikely as the thermodynamics are fairly unfavorable. However, at oxidation state +2 and +3 the breaking of the $\mathrm{C}-\mathrm{C}$ bond could occur based on thermodynamic grounds. So why is it barely observed experimentally? To answer this question, we have identified transition states for breaking the $\mathrm{C}-\mathrm{C}$ bond in the key intermediates at oxidation state +2 (Figure 6a) and +3 (Figure 6b).

The first, general observation is that the activation energies are quite high with about $1.3 \mathrm{eV}$, even on the $\operatorname{Pd}(100)$ surface which is more active than the $\mathrm{Pd}(111)$ surface. There are two barriers that differ significantly from this number. First, is the highest activation barrier for breaking the $\mathrm{C}-\mathrm{C}$ of the hydrate, $\mathrm{CH}_{3} \mathrm{CH}(\mathrm{OH})_{2}$ (oxidation state +2$)\left(\mathrm{E}^{\ddagger}=2.1 \mathrm{eV}\right)$. This large barrier is probably due to the fact that the carbons of the reactant are not interacting with the catalyst surface, hence they are not activated. 
Besides, the steric crowding which destabilizes both the transition state and the product, barely affects the reactant, which does not adsorb through a carbon atom but rather through the two lone-pair of electrons of the oxygen atoms. In support of this argument, we find that the energy barrier for the dehydrogenated geminal diol is significantly lower $(1.4 \mathrm{eV})$.
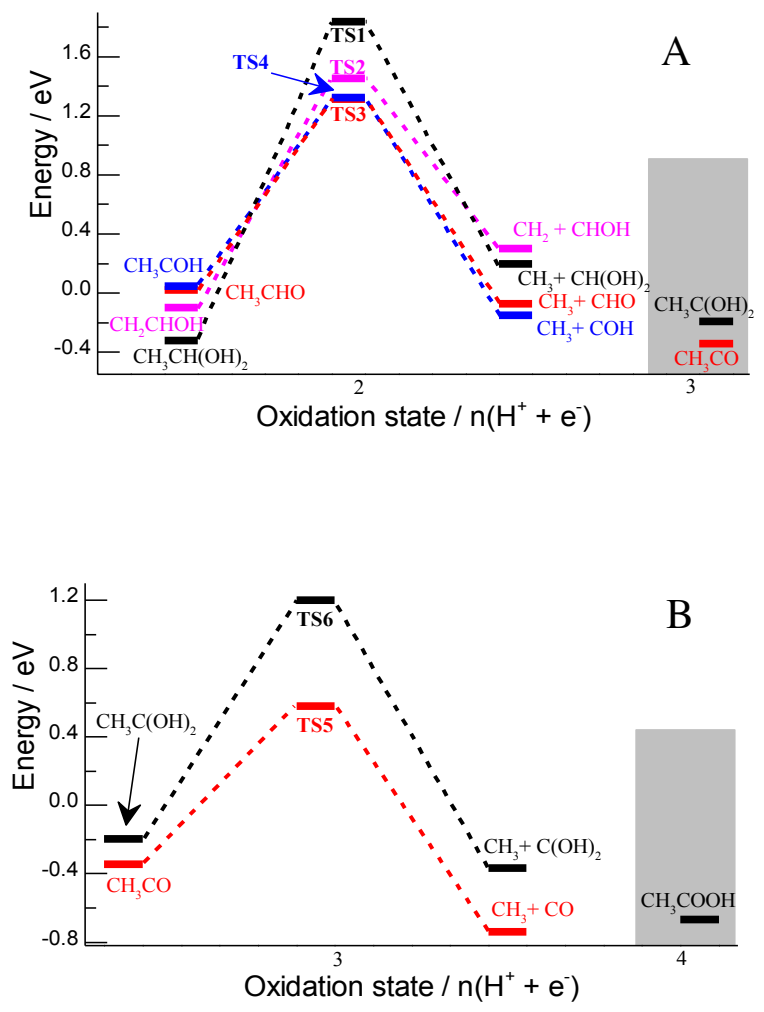

Figure 6: Energy profile for breaking the $\mathrm{C}-\mathrm{C}$ bond on $\mathrm{Pd}(100)$ for species at oxidation state two (A) and at oxidation state three (B), both at $0.26 \mathrm{~V}$ vs RHE.

In this case, the steric crowding in the reactant and product is similar, as both adsorb through the unsaturated carbon atom hence benefiting from less destabilization. Second, the lowest barrier for breaking $\mathrm{C}-\mathrm{C}$ bond is found for acetyl $\left(\mathrm{CH}_{3} \mathrm{CO}\right)$ with activation energy of "only" $0.9 \mathrm{eV}$, which is attributed to the very stable CO product on Pd surface. Note, however, that this is still a significant 
barrier at room temperature that cannot be lowered by the application of potential. Furthermore, the $\mathrm{C}-$ $\mathrm{C}$ splitting is in competition with the thermodynamically favorable $\mathrm{C}-\mathrm{OH}$ bond formation that yields acetic acid. Playing on the structure of the catalyst, one may favor the $\mathrm{C}-\mathrm{C}$ bond splitting since this is a structure-sensitive reaction that is favored on low-coordinated facets: the $\mathrm{C}-\mathrm{C}$ bond splitting in $\mathrm{CH}_{3} \mathrm{CO}$ drops from $1.4 \mathrm{eV}$ on $\operatorname{Pd}(111)^{76}$ to $0.9 \mathrm{eV}$ on $\operatorname{Pd}(100)$ and $0.7 \mathrm{eV}$ on $\operatorname{Pd}(110)^{77}$

The reaction selectivity towards acetic acid is better understood from the aforementioned reaction energy profiles, keeping in mind the $\mathrm{C}-\mathrm{H}$ and $\mathrm{O}-\mathrm{H}$ bond breaking in ethanol catalyzed by $\mathrm{Pd}$ have a barrier lower than $0.8 \mathrm{eV} .^{78}$ These steps can be even further activated by the presence of surface hydroxyls as shown in previous DFT studies. ${ }^{30,31}$ The thermodynamic impact of the recombination of $\mathrm{H}^{+}$ and $\mathrm{OH}^{-}$is, however, also included in our present study through the use of the computational hydrogen electrode. At oxidation state +2 the most stable intermediate (the gem-diol $\mathrm{CH}_{3} \mathrm{CH}(\mathrm{OH})_{2}$ ) does not undergo $\mathrm{C}-\mathrm{C}$ splitting $\left(\mathrm{E}^{\ddagger}=2.1 \mathrm{eV}\right)$ and also higher lying intermediates only react slowly towards $\mathrm{C}_{1}$ products and face a strong competition with $\mathrm{C}-\mathrm{OH}$ bond formation. Hence, the hydrate gets oxidized, despite the fact that this does not lead to the lowest energy intermediate at oxidation state +3 . At oxidation state +3 , there are three processes in competition. In one process, the $\mathrm{CH}_{3} \mathrm{C}(\mathrm{OH})_{2}$ is quickly oxidized to acetic acid $\left(\mathrm{E}^{\ddagger}<0.8 \mathrm{eV}\right)$ and the $\mathrm{C}-\mathrm{C}$ bond remains intact. In the second process, the most stable but kinetically less accessible intermediate $\mathrm{CH}_{3} \mathrm{CO}$, can undergo slow $\mathrm{C}-\mathrm{C}$ bond splitting $\left(\mathrm{E}^{\ddagger}=\right.$ $0.9 \mathrm{eV}$ ) and the fragments eventually be oxidized to $\mathrm{CO} / \mathrm{CO}_{2}$. In the third process, $\mathrm{CH}_{3} \mathrm{CO}$ can be oxidized to acetic acid as explained above, which is an electrochemical process that is favored by oxidative potentials. In other words, the necessary potentials and the unfavorable "connection" between the most stable intermediates lead to the dominance of acetic acid as a product and to the small probability of splitting the $\mathrm{C}-\mathrm{C}$ bond at an early stage of the oxidation process. These results show how challenging and complex it is to design a catalyst for complete electrooxidation of ethanol to $\mathrm{CO}_{2}$. 


\subsection{Ethanol electrooxidation mechanism}

In this section, we summarize the reaction scheme that results from our joint experimental and theoretical study as shown in scheme 1 .

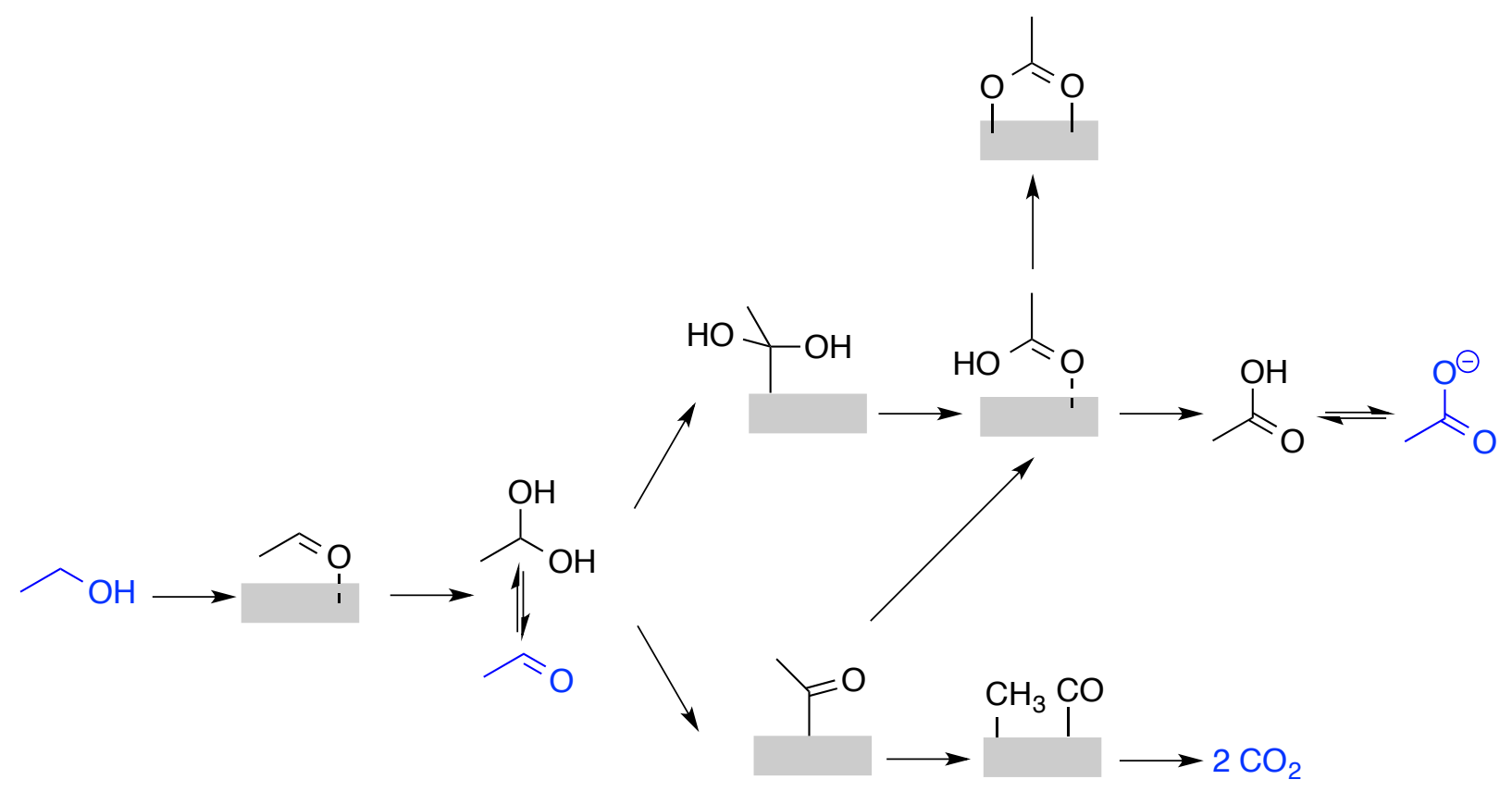

Scheme 1: General Reaction Scheme based on our results. In blue, the experimental evidences. In black, the intermediates as suggested by our DFT simulations. Most of the steps are catalyzed by the Pd electrode (single arrows) while others are solution equilibria (two one-sided arrows).

Ethanol is converted to acetaldehyde by oxidative dehydrogenation on $\mathrm{Pd}$. This is a two-step processes that has been studied in details by DFT simulations including co-adsorbed species and water solvent ${ }^{30}$ To be able to screen a much larger part of the reaction network of ethanol electrooxidation into $\mathrm{CO}_{2}$, we had to simplify our model to a Pd/vacuum interface. The effect of the co-adsorption of water are not included but expected to be negligible on the relative energies. ${ }^{79,80}$ Indeed, even if the details differ, our study leads to the same conclusion at oxidation state +2 : acetaldehyde is in equilibrium with its hydrate, the gem-diol. And acetaldehyde is seen in the bulk solution by PM-IRRAS. Then, two routes are in competition. First, the gem-diol is the most stable adsorbed species at its degree of oxidation. The $\alpha-\mathrm{C}-$ $\mathrm{H}$ bond breaking is particularly facilitated in electrochemical conditions and leads to $\mathrm{CH}_{3} \mathrm{C}(\mathrm{OH})_{2}$ that 
easily yields acetic acid. In the second route, acetaldehyde is dehydrogenated into acetyl, $\mathrm{CH}_{3} \mathrm{CO}$. Since acetaldehyde is less stable on the surface than its gem-diol, this route is disfavored. However, the acetyl is a pivotal intermediate. Its degree of oxidation is the first along the path where the key $\mathrm{C}-\mathrm{C}$ bond scission can occur exothermically from the most stable C2 fragment. Moreover among all the intermediates of degree +2 and +3 , it is the one that exhibits the lowest activation barrier for the $\mathrm{C}-\mathrm{C}$ bond scission $(0.9 \mathrm{eV})$. Hence, even though a chemical step, $\mathrm{CH}_{3} \mathrm{CO}$ decarbonylation could compete with the $\mathrm{C}-\mathrm{H}, \mathrm{O}-\mathrm{H}$ and $\mathrm{C}-\mathrm{OH}$ rearrangements that are facilitated by the electrochemical potential. Thus, the $\mathrm{CO}_{2}$ traces we have observed experimentally at low potentials by PM-IRRAS are probably generated from adsorbed acetyl. This is in line with the ATR-SEIRAS experiments of Yang et al. ${ }^{19}$ However, the acetyl can also easily lead to acetic acid by the formation of a $\mathrm{C}-\mathrm{OH}$ bond, a process that is accelerated by oxidative potentials. This explains the experimental observation that the selectivity towards $\mathrm{CO}_{2}$ decreases at higher potential.

In summary, the $\mathrm{C}-\mathrm{C}$ bond scission that is essential to open the route to a full oxidation of ethanol can occur at the degree of oxidation +3 . However, it is a slow process and in competition with the faster oxidation to acetic acid. For degree of oxidation $>+5$, the $\mathrm{C}-\mathrm{C}$ bond splitting is exothermic, opening the road to the $C_{1}$ pathway. However, there is a strong disconnection on the $C_{2}$ pathway between the most stable species at degree $+5\left(\mathrm{CH}_{3} \mathrm{COO}\right)$ and the most stable species at degree $+6(\mathrm{CHCOOH})$ that hinders the oxidation of acetate (Figure 5), in line with the experimentally observed impossibility to oxidize acetic acid in $\mathrm{KOH}$ under our conditions (Figure 1).

\section{Conclusion}

We have presented a comprehensive study of the reaction mechanism of ethanol electrooxidation over Pd surfaces, combining cyclic voltammetry $(\mathrm{CV})$, polarization modulation infrared reflection absorption 
spectroscopy (PM-IRRAS), and density functional theory (DFT) calculations. The PM-IRRAS information (identification of surface and bulk solution species) simplified the number of possible intermediates considered in the DFT modelling, while DFT insights provided invaluable information of the elementary reaction intermediates and kinetic parameters, which was not accessible experimentally. This strategy can be easily extended to other alcohols or organic molecules on other metal surfaces.

In this work, we have solved two of the long debated puzzles: the path leading to the formation of acetate, the product obtained over a Pd catalyst in alkaline conditions, and the most likely intermediates where the $\mathrm{C}-\mathrm{C}$ bond can be broken. For the formation of acetic acid, we have identified two converging paths: the most stable path, going through the gem-diol (hydrate of acetaldehyde), and the second most stable path going through the acetyl $\left(\mathrm{CH}_{3} \mathrm{CO}\right)$. Unfortunately, acetate cannot be oxidized further over Pd according to our CV and DFT results, closing the door to the $\mathrm{C} 1$ path and thus the complete oxidation of ethanol. Hence, to contribute to the second debate, we have determined the most likely intermediates where the $\mathrm{C}-\mathrm{C}$ bond can be broken before reaching acetate. We have demonstrated that acetyl (at oxidation state three) has by far $(>0.3 \mathrm{eV})$ the lowest activation energy for the $\mathrm{C}-\mathrm{C}$ bond breaking $\left(\mathrm{E}^{\ddagger}\right.$ $=0.9 \mathrm{eV})$. However, the over-potentials required for reasonable current densities are strongly accelerating the electrochemical oxidation process. This favors the $\mathrm{C}-\mathrm{OH}$ formation over the $\mathrm{C}-\mathrm{C}$ splitting reaction. Therefore, $\mathrm{CH}_{3} \mathrm{CO}$ is quickly oxidized to acetic acid, thereby suppressing the $\mathrm{C}-\mathrm{C}$ bond breaking, explaining the negligible amount of $\mathrm{CO}_{2}$ detected at higher potentials. In other words, $\mathrm{CH}_{3} \mathrm{CO}$ plays a pivotal role since it can either undergo a $\mathrm{C}-\mathrm{C}$ bond splitting, eventually yielding $\mathrm{CO}_{2}$, or be oxidized towards $\mathrm{CH}_{3} \mathrm{COOH}$, a dead end in the reaction scheme. Through this analysis, our work has determined the conditions for a better selectivity towards $\mathrm{CO}_{2}$ : destabilize the gem-diol, stabilize the acetyl and facilitate its splitting into $\mathrm{CH}_{3}$ and $\mathrm{CO}$. A large descriptor-based search of catalysts is being started to find in silico alloy formulations that would obey to these conditions. 


\section{Acknowledgement}

The authors thank University of Ottawa, CNRS and ENS Lyon for support in the frame of the associated international laboratory FUNCAT "Fundamental catalysis for green chemistry: From welldefined active sites to mechanistic explorations", Natural Sciences and Engineering Research Council of Canada (NSERC) for financial support, Canada Foundation for Innovation (CFI) for equipment funding and the PSMN and Compute Canada (Sharcnet) for the computational resources.

Supporting Information Available: The physical characterization of the Pd/C nanoparticles; the PMIRRAS background/reference and Data processing and interpretation details; FTIR transmission spectra for $\mathrm{KOH}$ and ( $\mathrm{KOH}+$ acetic acid, sodium acetate, sodium carbonate, and ethanol); most stable geometric ethanol oxidation intermediates structures and some of the key POSCAR files. This material is available free of charge via the Internet at http://pubs.acs.org

\section{References}

(1) Heinzel, A.; Cappadonia, M.; Stimming, U.; Kordesch, K. V.; Tambasco de Oliveira, J. C. In Ullmann 's Encyclopedia of Industrial Chemistry; Wiley-VCH, 2010.

(2) Jiang, S. P.; Wang, X. In Solid State Electrochem. II; Wiley-VCH Verlag GmbH \& Co. KGaA, 2011; pp. 179-264.

(3) Steele, B. C. H.; Heinzel, A. Nature 2001, 414, 345-352.

(4) Zhang, S.; Shao, Y.; Yin, G.; Lin, Y. J. Mater. Chem. 2013, 1, 4631-4641.

(5) An, L.; Zhao, T. S.; Li, Y. S. Renew. Sustain. Energy Rev. 2015, 50, 1462-1468.

(6) Goldemberg, J. Science 2007, 315, 808-810.

(7) Nørskov, J. K.; Rossmeisl, J.; Logadottir, A.; Lindqvist, L.; Kitchin, J. R.; Bligaard, T.; Jónsson, H. J. Phys. Chem. B 2004, 108, 17886-17892.

(8) Varcoe, J. R.; Atanassov, P.; Dekel, D. R.; Herring, A. M.; Hickner, M. A.; Kohl, P. A.; Kucernak, A. R.; Mustain, W. E.; Nijmeijer, K.; Scott, K.; Xu, T.; Zhuang, L.; Zhuang; Zhuang; Zhuang; Zhuang; Zhuang. Energy \& Environ. Sci. 2014, 7, 3135-3191.

(9) Fujiwara, N.; Siroma, Z.; Yamazaki, S.; Ioroi, T.; Senoh, H.; Yasuda, K. J. Power Sources 2008, $185,621-626$.

(10) Ma, L.; Chu, D.; Chen, R. Int. J. Hydrog. Energy 2012, 37, 11185-11194.

(11) Bianchini, C.; Shen, P. K. Chem. Rev. 2009, 109, 4183-4206.

(12) Fang, X.; Wang, L.; Shen, P. K.; Cui, G.; Bianchini, C. J. Power Sources 2010, 195, 1375-1378.

(13) Xu, C.; Shen, P. kang; Liu, Y. J. Power Sources 2007, 164, 527-531.

(14) Martinez, U.; Serov, A.; Padilla, M.; Atanassov, P. ChemSusChem 2014, 7, 2351-2357. 
(15) M. Koper, M. T.; S. Lai, S. C. Faraday Discuss. 2009, 140, 399-416.

(16) Tremiliosi-Filho, G.; Gonzalez, E. R.; Motheo, A. J.; Belgsir, E. M.; Leger, J.-M.; Lamy, C. J. Electroanal. Chem. 1998, 444, 31-39.

(17) Tarasevich, M. R.; Korchagin, O. V. Russ. J. Electrochem. 2013, 49, 600-618.

(18) Geraldes, A. N.; Furtunato da Silva, D.; Martins da Silva, J. C.; Antonio de Sá, O.; Spinacé, E. V.; Neto, A. O.; Coelho dos Santos, M. J. Power Sources 2015, 275, 189-199.

(19) Yang, Y.-Y.; Ren, J.; Li, Q.-X.; Zhou, Z.-Y.; Sun, S.-G.; Cai, W.-B. ACS Catal. 2014, 4, 798-803.

(20) Zhou, Z.-Y.; Sun, S.-G. Electrochim. Acta 2005, 50, 5163-5171.

(21) Zhou, Z.-Y.; Wang, Q.; Lin, J.-L.; Tian, N.; Sun, S.-G. Electrochimica Acta 2010, 55, 7995-7999.

(22) Christensen, P. A.; Jones, S. W. M.; Hamnett, A. J. Phys. Chem. C 2012, 116, 24681-24689.

(23) Christensen, P. A.; Linares-Moya, D. J. Phys. Chem. C 2010, 114, 1094-1101.

(24) Christensen, P. A.; Hamnett, A.; Linares-Moya, D. Phys. Chem. Chem. Phys. 2011, 13, 1173911747.

(25) Christensen, P. A.; Jones, S. W. M. J. Phys. Chem. C 2014, 118, 29760-29769.

(26) Cantane, D. A.; Lima, F. H. B. Electrocatalysis 2012, 3, 324-333.

(27) Liu, J.; Ye, J.; Xu, C.; Jiang, S. P.; Tong, Y. Electrochem. Commun. 2007, 9, 2334-2339.

(28) Liang, Z. X.; Zhao, T. S.; Xu, J. B.; Zhu, L. D. Electrochimica Acta 2009, 54, 2203-2208.

(29) Schnur, S.; Groß, A. Catal. Today 2011, 165, 129-137.

(30) Hibbitts, D. D.; Neurock, M. J. Catal. 2013, 299, 261-271.

(31) Sheng, T.; Lin, W.-F.; Hardacre, C.; Hu, P. J. Phys. Chem. C 2014, 118, 5762-5772.

(32) Delpeuch, A. B.; Chatenet, M.; Rau, M. S.; Cremers, C. Phys. Chem. Chem. Phys. 2015, 17, 10881-10893.

(33) Ferrin, P.; Mavrikakis, M. J. Am. Chem. Soc. 2009, 131, 14381-14389.

(34) Ferrin, P.; Nilekar, A. U.; Greeley, J.; Mavrikakis, M.; Rossmeisl, J. Surf. Sci. 2008, 602, 34243431 .

(35) Rossmeisl, J.; Ferrin, P.; Tritsaris, G. A.; Nilekar, A. U.; Koh, S.; Bae, S. E.; Brankovic, S. R.; Strasser, P.; Mavrikakis, M. Energy \& Environ. Sci. 2012, 5, 8335-8342.

(36) Anderson, A. B.; Albu, T. V. J. Am. Chem. Soc. 1999, 121, 11855-11863.

(37) Lozovoi, A. Y.; Alavi, A. Phys. Rev. B: Condens. Matter Mater. Phys. 2003, 68, 245416/1$245416 / 18$.

(38) Otani, M.; Sugino, O. Phys. Rev. B: Condens. Matter Mater. Phys. 2006, 73, 115407/1-115407/11.

(39) Taylor, C.; Wasileski, S.; Filhol, J.-S.; Neurock, M. Phys. Rev. B 2006, 73.

(40) Fang, Y.-H.; Liu, Z.-P. J. Phys. Chem. C 2009, 113, 9765-9772.

(41) Skulason, E.; Karlberg, G. S.; Rossmeisl, J.; Bligaard, T.; Greeley, J.; Jonsson, H.; Norskov, J. K. Phys. Chem. Chem. Phys. 2007, 9, 3241-3250.

(42) Mathew, K.; Sundararaman, R.; Letchworth-Weaver, K.; Arias, T. A.; Hennig, R. G. J. Chem. Phys. 2014, 140, 084106/1-084106/8.

(43) Jinnouchi, R.; Anderson, A. B. Phys. Rev. B 2008, 77, 245417-245435.

(44) Filhol, J.-S.; Neurock, M. Angew. Chem., Int. Ed. 2006, 45, 402-406.

(45) Steinmann, S. N.; Michel, C.; Schwiedernoch, R.; Filhol, J.-S.; Sautet, P. ChemPhysChem 2015, 16, 2307-2311.

(46) Janik, M.; Taylor, C.; Neurock, M. Top. Catal. 2007, 46, 306-319.

(47) Fang, Y.-H.; Wei, G.-F.; Liu, Z.-P. Theoretical modeling of electrode/electrolyte interface from first-principles periodic continuum solvation method. Catalysis Today, 2013, 202, 98-104.

(48) Figlarz, M.; Fievet, F.; Lagier, J. P. Reduction of metal compounds to metal powders by polyols., 
June 22, 1984.

(49) Monyoncho, E. A.; Ntais, S.; Soares, F.; Woo, T. K.; Baranova, E. A. J. Power Sources 2015, 287, $139-149$.

(50) Zamlynny, V.; Lipkowski, J. In Advances in Electrochemical Science and Engineering: Diffraction and Spectroscopic Methods in Electrochemistry; Wiley-VCH Verlag GmbH, 2006; Vol. 9, pp. 315-376.

(51) Golden, W. G.; Dunn, D. S.; Overend, J. J. Catal. 1981, 71, 395-404.

(52) Kresse, G.; Hafner, J. Phys. Rev. B: Condens. Matter 1993, 48, 13115-13118.

(53) Kresse, G.; Furthmueller, J. Phys. Rev. B: Condens. Matter 1996, 54, 11169-11186.

(54) Perdew, J. P.; Burke, K.; Ernzerhof, M. Phys. Rev. Lett. 1996, 77, 3865-3868.

(55) Kresse, G.; Joubert, D. Phys. Rev. B: Condens. Matter Mater. Phys. 1999, 59, 1758-1775.

(56) Bloechl, P. E. Phys. Rev. B: Condens. Matter 1994, 50, 17953-17979.

(57) Methfessel, M.; Paxton, A. T. Phys. Rev. B 1989, 40, 3616-3621.

(58) Henkelman, G.; Jonsson, H. J. Chem. Phys. 2000, 113, 9978-9985.

(59)Fleurat-Lessard, P.; Dayal, P. Opt'n Path http://perso.ens-lyon.fr/paul.fleuratlessard/ReactionPath.html (accessed 2015).

(60) Henkelman, G.; Jonsson, H. J. Chem. Phys. 1999, 111, 7010-7022.

(61) Hafner, D. K. and T. B. and J. J. Physics: Condens. Matter 2010, 22, 265006.

(62) Mennucci, B.; Cancès, E.; Tomasi, J. J. Phys. Chem. B 1997, 101, 10506-10517.

(63) Frisch, M. J.; Fox, D. J.; Cioslowski, J.; Ortiz, J. V.; Foresman, J. B.; Farkas, O.; Daniels, A. D.; Dapprich, S.; Dannenberg, J. J.; Salvador, P.; Voth, G. A.; Zakrzewski, V. G.; Morokuma, K.; Martin, R. L.; Ochterski, J. W.; Pomelli, C.; Cammi, R.; Austin, A. J.; Yazyev, O.; Stratmann, R. E.; Gomperts, R.; Jaramillo, J.; Adamo, C.; Bakken, V.; Cross, J. B.; Knox, J. E.; Klene, M.; Millam, J. M.; Rega, N.; Cossi, M.; Tomasi, J.; Iyengar, S. S.; Burant, J. C.; Rendell, A.; Raghavachari, K.; Normand, J.; Kobayashi, R.; Staroverov, V. N.; Kudin, K. N.; Brothers, E.; Heyd, J. J.; Bearpark, M.; Ogliaro, F.; Peralta, J., J. E.; Montgomery, J. A.; Vreven, T.; Nakai, H.; Kitao, O.; Honda, Y.; Nakajima, T.; Ishida, M.; Hasegawa, J.; Fukuda, R.; Toyota, K.; Ehara, M.; Hada, M.; Sonnenberg, J. L.; Zheng, G.; Bloino, J.; Izmaylov, A. F.; Hratchian, H. P.; Li, X.; Caricato, M.; Nakatsuji, H.; Petersson, G. A.; Mennucci, B.; Barone, V.; Scalmani, G.; Cheeseman, J. R.; Robb, M. A.; Scuseria, G. E.; Schlegel, H. B.; Trucks, G. W. Gaussian09, 2013.

(64) Habibi, B.; Mohammadyari, S. Int. J. Hydrog. Energy 2015, 40, 10833-10846.

(65) Schechter, J. M.; Yang, Y.; Li, X.; Zhao, Y. RSC Adv. 2016, 6, 5384-5390.

(66) Monyoncho, E. A.; Ntais, S.; Brazeau, N.; Wu, J.-J.; Sun, C.-L.; Baranova, E. A. ChemElectroChem 2016, 3, 218-227.

(67) Ferreira Jr., R. S.; Janete Giz, M.; Camara, G. A. J. Electroanal. Chem. 2013, 697, 15-20.

(68) Christensen, P. A.; Jones, S. W. M.; Hamnett, A. Phys. Chem. Chem. Phys. 2013, 15, 1726817276.

(69) Rudolph, W. W.; Fischer, D.; Irmer, G. Dalton Trans. 2014, 43, 3174-3185.

(70) Sutton, C. C. R.; Franks, G. V.; da Silva, G. Spectrochim. Acta Part A: Mol. Biomol. Spectrosc. 2015, 134, 535-542.

(71) Alcala, R.; Mavrikakis, M.; Dumesic, J. A. J. Catal. 2003, 218, 178-190.

(72) Wang, E. D.; Xu, J. B.; Zhao, T. S. J. Phys. Chem. C 2010, 114, 10489-10497.

(73) Buso-Rogero, C.; Grozovski, V.; Vidal-Iglesias, F. J.; Solla-Gullon, J.; Herrero, E.; Feliu, J. M. J. Mater. Chem. 2013, 1, 7068-7076.

(74) Li, H.; Calle-Vallejo, F.; Kolb, M. J.; Kwon, Y.; Li, Y.; Koper, M. T. M. J. Am. Chem. Soc. 2013, 135, 14329-14338. 
(75) Steinmann, S. N.; Michel, C.; Schwiedernoch, R.; Wu, M.; Sautet, P. J. Catal. 2016 in press.

(76) Li, M.; Guo, W.; Jiang, R.; Zhao, L.; Shan, H. Langmuir 2010, 26, 1879-1888.

(77) Guo, W.; Li, M.; Lu, X.; Zhu, H.; Li, Y.; Li, S.; Zhao, L. Dalton Trans. 2013, 42, 2309-2318.

(78) Zaffran, J.; Michel, C.; Delbecq, F.; Sautet, P. J. Phys. Chem. C 2015, 119, 12988-12998.

(79) Michel, C.; Zaffran, J.; Ruppert, A. M.; Matras-Michalska, J.; Jedrzejczyk, M.; Grams, J.; Sautet, P. Chem. Commun. 2014, 50, 12450-12453.

(80) Loffreda, D.; Michel, C.; Delbecq, F.; Sautet, P. J. Catal. 2013, 308, 374-385.

\section{Graphical Abstract}

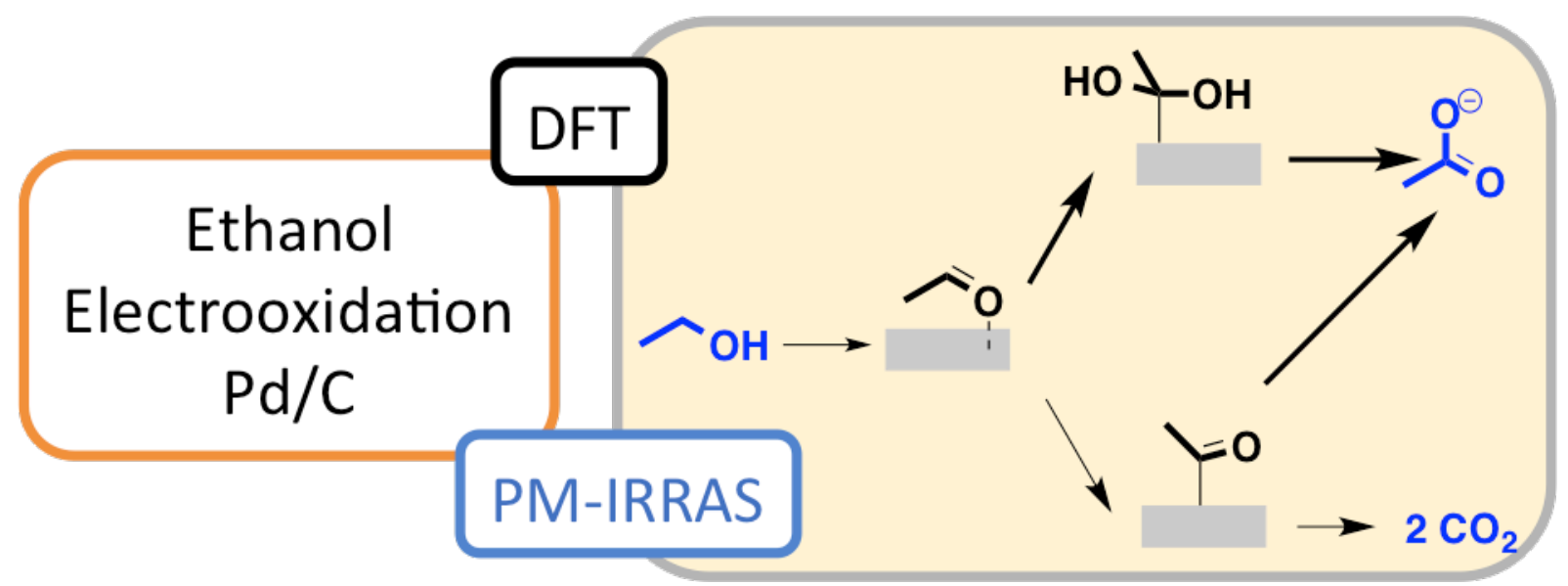

